\title{
El comercio minorista en el centro de Madrid
}

\author{
Adelaida Checa Sánchez * \\ Gloria LoRA-Tamayo D'OCON **
}

\section{INTRODUCCIÓN}

Las transformaciones experimentadas en el municipio durante los últimos años han afectado profundamente al Centro de Madrid. La expansión de la ciudad y la descentralización de los servicios, con la creación de focos de actividad en los distritos periféricos y en el área metropolitana, han debilitado el poder de atracción del centro tradicional.

El deterioro del caserío en muchas zonas del área, sobre todo en las que quedan fuera de los ejes representativos y las vías de conexión con otros centros funcionales; los problemas de accesibilidad en vehículo rodado; la disminución de la población, y el envejecimiento de la misma, contribuyen a esta pérdida de protagonismo.

A pesar de ello, el "centro" como área comercial sigue teniendo vigencia, y su estudio es de interés singular.

Este artículo es una aproximación al análisis del comercio minorista del Centro de Madrid, su estructura sectorial y espacial y las transformaciones recientes.

El espacio de estudio es el casco histórico, comprendido dentro de los límites del actual distrito Centro: por el norte los Bulevares (calles de Alberto Aguilera, Carranza, Sagasta y Génova); al sur las rondas (de Segovia, Toledo, Valencia y Atocha); al este los paseos del Prado y de Recoletos, y al oeste la calle Segovia, el río Manzanares, la Cuesta de San Vicente y la calle de la Princesa.

* Profa. Titular Univ. Dep. Análisis Geográfico Regional y Geografía Física. U.C.M.

* Colaboradora Honorífica. Dep. Análisis Geográfico Regional y Geografía Física. U.C.M. 


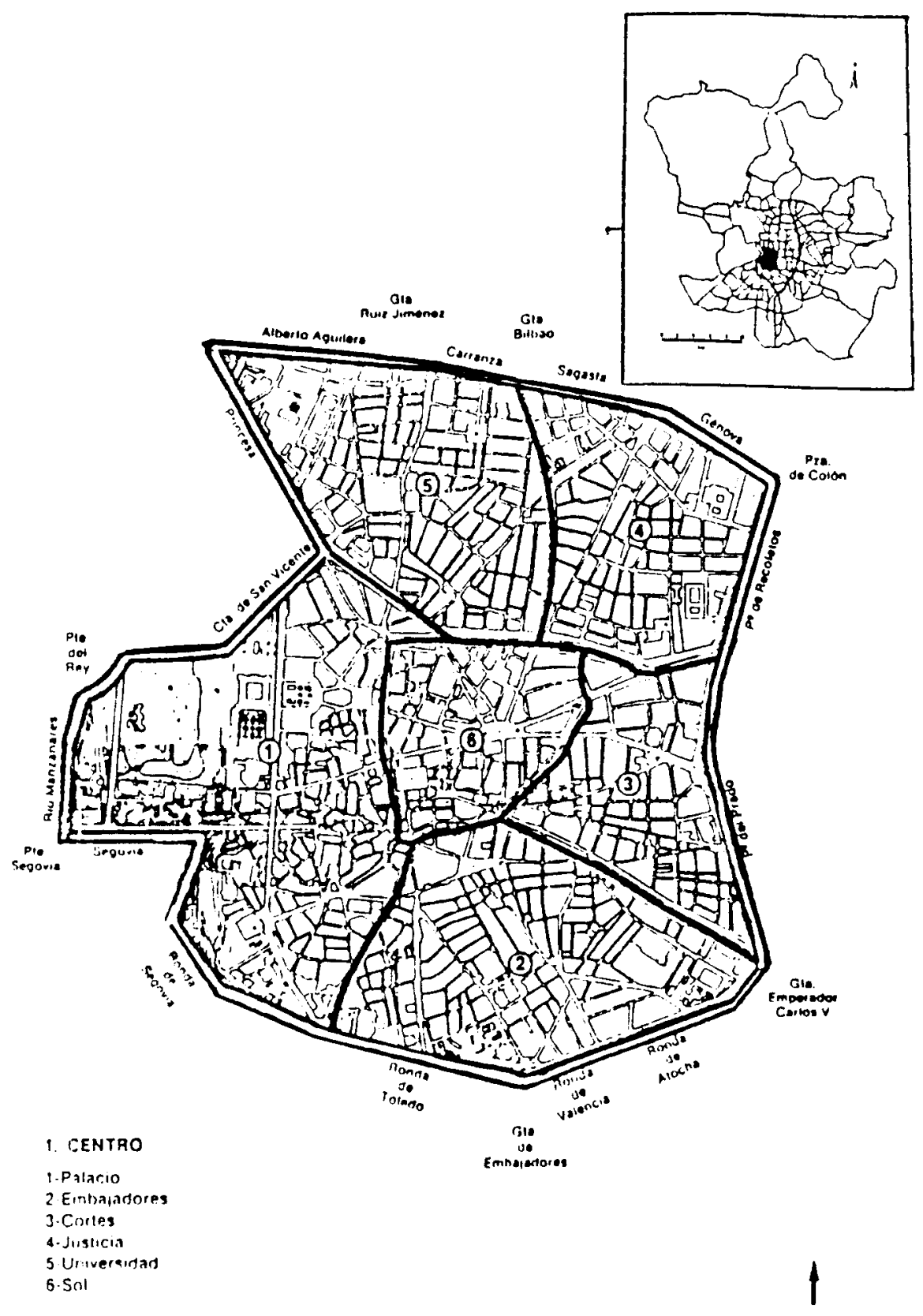

Fig. 1. Distrito Centro: Situación y División Administrativa. 
El territorio ocupa 519 Has, una superficie inferior al $1 \%$ del total municipal. Comprende los barrios de:

- 1.1 Palacio, con 148,05 Has y 23.622 habitantes.

- 1.2 Embajadores, con 103 Has y 45.079 habitantes.

- 1.3 Cortes, con 59,20 Has y 11.271 habitantes.

- 1.4 Justicia, con 61,20 Has y 16.625 habitantes.

- 1.5 Universidad, con 103,35 Has y 32.151 habitantes.

- $1.6 \mathrm{Sol}$, con 44,30 Has y 7.377 habitantes.

Se han revisado las fuentes disponibles para el estudio de los establecimientos minoristas de Madrid. De entre ellas destacamos las Licencias Fiscales de la Cámara Oficial de Comercio e Industria de Madrid, el Censo de Locales del Instituto Nacional de Estadística, el Padrón de Radicación de Empresas del Ayuntamiento de Madrid y el Censo de Establecimientos Comerciales Minoristas de la Comunidad Autónoma de Madrid.

Esta última fuente, elaborada en 1986, demostró ser la más fiable y completa, a pesar del problema de la duplicidad de muchos establecimientos. Sin embargo, la deficiente actualización de la base de datos creada por este organismo, invalida en el momento actual su uso, como hemos podido comprobar sobre el terreno.

En consecuencia, la fuente utilizada para el presente estudio es el trabajo de campo realizado personalmente durante los meses de enero a marzo de 1992.

Mediante él se puede analizar la estructura sectorial y espacial del comercio minorista en el área. Queda fuera de nuestra intención y del objetivo de este trabajo abordar aspectos como las características de los establecimientos - superficie construida, superficie de venta, sistema de venta, número de cajas registradoras, existencia de scanner, etc...- y el nivel de empleo.

\section{LA FUNCIÓN COMERCIAL DEL CENTRO DE MADRID}

Ya en 1830 se puede considerar Madrid como un auténtico centro comercial, con las caracteristicas propias de la época. El plano de la Villa en esa fecha coincide prácticamente con los límites del distrito Centro, si exceptuamos el amplio recinto del Retiro.

Según la Matrícula de Comercio realizada en marzo de 1830, el número de establecimientos comerciales de Madrid era de 3.092 , de los que el $31,5 \%$ eran de alimentación; el $22,3 \%$ eran del sector textil; el $17,6 \%$ de 
uso y regalo; el $12,9 \%$ de hogar; el $3,0 \%$ de productos químicos; el $8,3 \%$ otros establecimientos, y el $4,3 \%$ sin especificar.

El número de comercios por 1.000 habitantes era de 17 en esa fecha, índice muy elevado si lo comparamos con el de 1986 que se cifra en 14,7 para el conjunto de la ciudad actual. Hay que tener en cuenta las características de los comercios de una y otra época: en 1830, aunque el comercio ambulante había decaido ya en beneficio del fijo, la mayoría de los establecimientos tenian una reducida superficie, ocupando parte de un portal y con más carácter de puesto o banca que de local.

A pesar de que el tipo de comercio predominante respondía a una economía de subsistencia o de necesidades, el hecho de ser Madrid Corte y Capital de España, contribuyó considerablemente al desarrollo de la actividad comercial, al tiempo que se fue incrementando la gama de establecimientos propios de una economía de apetencia, o lo que podríamos denominar comercio de lujo: de blondas, encajes, joyerías, loza, etc.

La afluencia de visitantes a la capital fue, sin duda, un factor impulsor de la actividad comercial.

Sobre las características de este comercio existen muchas noticias en la literatura del siglo pasado. Recordemos las jugosas descripciones de los artículos periodísticos de Mesonero Romanos y de las novelas, algo posteriores, de Pérez Galdós.

La distribución espacial del comercio no era homogénea en toda la superficie del Madrid de entonces.

Las mayores densidades comerciales se daban en el centro de la ciudad, en el entorno de la Puerta del Sol, al sur de la línea marcada por las calles del Arenal y de Alcalá, y hasta aproximadamente las calles de Colegiata y la Magdalena. En esta zona los barrios más comerciales eran: La Cruz, Santa Cruz, La Panaderia, San Ginés, San Justo, y secundariamente Santo Tomás y La Trinidad. De todos ellos, el de mayor actividad, con mucho, era el barrio de La Cruz, delimitado por las calles de Carretas, Huertas, Príncipe y Carrera de San Jerónimo. El resto de los barrios comerciales se localizaban, sobre todo, al oeste del barrio de La Cruz, en el entorno de las calles Arenal, Mayor y Platerías, y en las proximidades de la Plaza Mayor.

Otro núcleo comercial, más pequeño, se localizaba en Lavapiés, en el barrio del Ave María, zona muy popular. Por último, al norte, los barrios de San Ildefonso y San Basilio constituian otro pequeño núcleo de actividad comercial, localizado en torno a las Correderas Alta y Baja de San Pablo, hasta la calle Fuencarral al este. 
Con el crecimiento de la ciudad a lo largo del pasado siglo y en el actual, la localización central del casco histórico de Madrid, su accesibilidad y buena comunicación siguieron favoreciendo su desarrollo como centro comercial del conjunto de la ciudad.

Las transformaciones experimentadas en la sociedad y en las estructuras comerciales tuvieron su primera plasmación precisamente en este área: los Grandes Almacenes y los Almacenes Populares se localizan aquí en las primeras décadas del presente siglo, reforzando el poder de atracción comercial del centro.

Es en la época actual cuando la falta de espacio y el precio del suelo dificultan el establecimiento de otras nuevas formas comerciales en auge, todas ellas de gran superficie.

Los cambios en los estilos de vida operados en la sociedad española en las últimas décadas, van de la mano de muchas de las transformaciones experimentadas en la estructura comercial de Madrid, que afectan al Centro de manera directa. El aumento de la renta per cápita, la incorporación de la mujer al trabajo, la elección de áreas distantes del centro como lugar de residencia y la extensión del automóvil, son algunos de los factores que se citan habitualmente como impulsores de nuevas formas comerciales - Hipermercados y Centros Comerciales, fundamentalmente-, en oposición a los tipos tradicionales de comercio minorista del Centro.

Las transformaciones en los hábitos de compra de la población son consecuencia de los cambios sociales. Al mismo tiempo, están influidos por las nuevas formas comerciales y por los avances de la técnica, entre ellos la difusión del congelador. Ha disminuido la frecuencia de compra, y ésta se ha convertido en una actividad familiar y de ocio, enmarcada en amplios espacios de moderna estructura y con áreas de esparcimiento localizados en las proximidades de las áreas residenciales o de las grandes vías de salida de la ciudad, con fácil acceso.

Con todo, el Centro sigue teniendo una importante actividad comercial. En 1986, fecha del Censo de Establecimientos Comerciales Minoristas realizado por la C.A.M., ya mencionado, el distrito reunía 5.615 establecimientos comerciales activos, que suponían el $12 \%$ de los del conjunto de Madrid. El índice de comercios por 1.000 habitantes era de 34,0 el más elevado de todos los distritos de la ciudad, muy por encima de la media y del segundo distrito comercial de Madrid (Salamanca) que contaba con 21,4 comercios por mil habitantes en la fecha.

También la densidad de comercios por hectárea era la más elevada en el distrito Centro, 10,8. La densidad del conjunto de Madrid era de 
0,8, y el distrito de Salamanca tenía 7,3. En metros cuadrados de superficie de venta por mil habitantes también ocupaba Centro el primer lugar con 1.557, aunque esta vez seguido a muy corta distancia de Salamanca, con 1.333 metros cuadrados por mil habitantes. Este último distrito es el que cuenta con una superficie media de venta mayor de todo Madrid.

En número de empleados por establecimiento, ocupaba Centro, junto con Salamanca, el primer lugar con 2,82. Por último, el distrito Centro destacaba, aunque seguido a corta distancia por el de Salamanca, en cuanto a la proporción de comercio ocasional, con el 58,2\% del total de sus establecimientos.

En 1992 el número de establecimientos comerciales del distrito - según trabajo de campo- era de 5.662. No contamos con datos fiables para el conjunto de Madrid en esa fecha, sin embargo, del proyecto de investigación realizado personalmente para la C.A.M. sobre el comecio minorista en la "almendra» de Madrid, se deduce que el distrito cuenta hoy en día con el $26,1 \%$ del total de comercios de la "almendra", constituyendo en la actualidad el núcleo comercial más importante.

\section{ESTRUCTURA SECTORIAL DE LA ACTIVIDAD COMERCIAL}

El carácter de centro comercial con amplio radio de influencia del distrito Centro viene dado por el importante volumen y proporción de los comercios de uso ocasional en relación con los de uso habitual. En este sentido, resulta interesante la comparación de la estructura por sectores de la actividad comercial entre la zona de estudio, la "almendra" y el conjunto de Madrid.

El cuadro 1 refleja las diferencias sectoriales de los tres ámbitos. Los datos correspondientes al distrito Centro son el resultado del trabajo de campo realizado en 1992. Los del resto de los distritos de la "almendra" corresponden a la misma fecha y se basan en los listados actualizados del Censo de establecimientos comerciales minoristas, facilitados por la CAM, corregidos parcial o totalmente mediante trabajo de campo. Los datos de Madrid son los elaborados por la CAM a partir del Censo de 1986.

El sector Alimentación, el más representado en los tres ámbitos espaciales, tiene sin embargo, en el distrito Centro una menor importancia, suponiendo únicamente el $27,3 \%$ del total de establecimientos comerciales, frente al $42,1 \%$ de Madrid y el $32,9 \%$ de la «almendra».

En relación con la estructura sectorial de los otros ámbitos espaciales, destaca Centro con un gran peso en el sector "Otros comercios", que suponen casi una cuarta parte del total de establecimientos del distrito. 
CUADRO 1. ESTRUCTURA SECTORIAL DE LA ACTIVIDAD COMERCIAL

\begin{tabular}{|c|c|c|c|c|}
\hline & ESPACIO & CENTRO & ALMENDRA & MADRID \\
\hline & AÑO: & 1992 & 1992 & 1986 \\
\hline & ACTIVIDAD & $\%$ & $\%$ & $\%$ \\
\hline 100 & & 27,3 & 32,9 & 42,1 \\
\hline 200 & 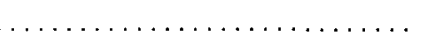 & 22,3 & 20,1 & 16,6 \\
\hline 300 & & 6,0 & 7,3 & 8,6 \\
\hline 400 & $\ldots$ & 18,6 & 16,9 & 14,3 \\
\hline 500 & & 1,4 & 3,1 & 2,4 \\
\hline 600 & $\ldots \ldots \ldots \ldots \ldots \ldots \ldots$ & 0,2 & 0,3 & 0,2 \\
\hline 700 & $\ldots \ldots \ldots \ldots \ldots \ldots \ldots \ldots \ldots$ & 23,2 & 17,8 & 13,7 \\
\hline 800 & $\ldots \ldots \ldots \ldots \ldots \ldots \ldots$ & 1,0 & 1,6 & 2,1 \\
\hline \multicolumn{2}{|l|}{ TOTAL } & 100,0 & 100,0 & 100,0 \\
\hline
\end{tabular}

Fuentes: Trabajo de campo; listados actualizados del Censo de Establecimientos Comerciales Minoristas de la CAM, y Censo de Establecimientos Comerciales Minoristas de la CAM. Datos Estadísticos. Elaboración propia.

Claves de actividades:

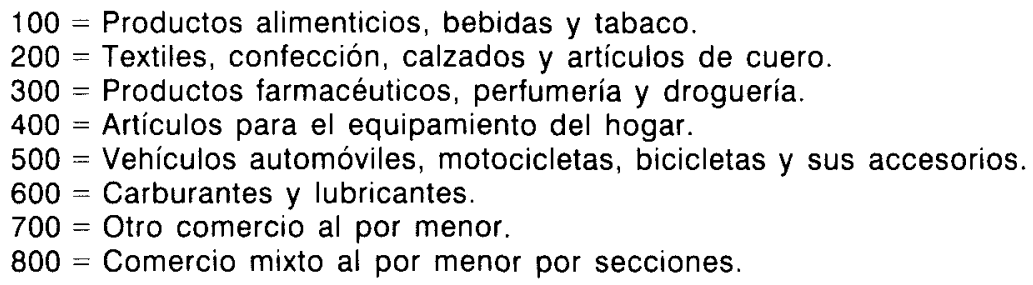

En segundo lugar, y también con proporciones más elevadas que en Madrid y la "almendra», destacan el sector "Textil», con más de una quinta parte del total de establecimientos, y el sector de "Equipamiento del hogar», también con un importante peso en la estructura.

Una menor representación que en los otros ámbitos tienen los sectores "Farmacia-Droguería-Perfumería", "Vehículos automóviles y sus accesorios" y el "Comercio mixto al por menor", aunque dentro de este último sector se cuentan tres Grandes Almacenes de gran superficie y tres Almacenes Populares.

La importancia comercial del distrito Centro queda resaltada al analizar el peso de sus establecimientos comerciales con relación a la "almendra».

Contando únicamente con el $12,4 \%$ de la superficie de la "almendra" $y$ el $13,5 \%$ de su población, posee el $26,13 \%$ del total de comercios. Dentro de ello, destaca con el $34 \%$ del total de comercios del grupo 700 , 

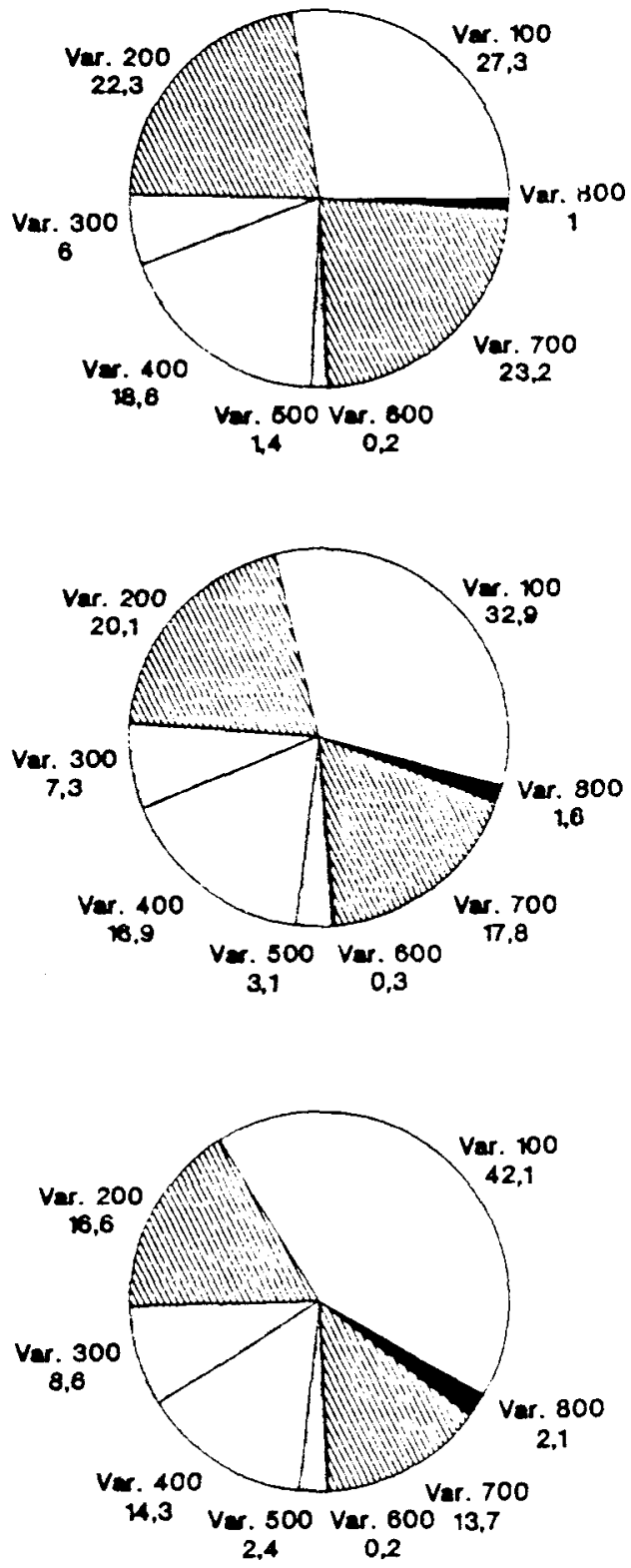

\section{Centro (1992)}

\section{Almendra (1992)}

\section{Madrid (1986)}

Fig. 2. Estructura sectorial de la actividad comercial en el distrito Centro, la Almendra y el conjunto de Madrid. 
el $29 \%$ del grupo 200 y el $28,8 \%$ del 400 . Ello pone de manifiesto la especialización del distrito Centro en los sectores Otros comercios, Textil y Hogar. Además de estos sectores, reúne la mayor proporción de comercios de la "almendra" en los sectores Alimentación y Farmacia-Perfumería-Droguería.

Centro cuenta con 44,34 comercios por mil habitantes y 10,91 comercios por hectárea, situándose a la cabeza de los distritos que componen la "almendra» en los dos índices. El conjunto de ésta tiene 22,95 comercios por mil habitantes y 5,20 comercios por hectárea.

La importante diferencia entre población, superficie y número de comercios demuestra que Centro es un distrito exportador para el resto de Madrid y foco de atracción de foráneos.

En el cuadro 2 se observa la estructura comercial del distrito a nivel subsectorial.

CUADRO 2. DISTRITO CENTRO

ESTRUCTURA COMERCIAL POR SUBSECTORES DE ACTIVIDAD

\begin{tabular}{c|r|r|r}
\hline \multirow{2}{*}{$\begin{array}{c}\text { SECTORES Y SUBSECTORES } \\
\text { DE ACTIVIDAD }\end{array}$} & \multicolumn{3}{|c}{} \\
\cline { 2 - 4 } & $\begin{array}{c}\text { N. DE } \\
\text { COMERCIOS }\end{array}$ & $\begin{array}{c}\% \text { COMERCIOS } \\
\text { DEL DISTRITO }\end{array}$ & $\begin{array}{c}\% \text { COMERCIOS DE } \\
\text { LA “ALMENDRAn }\end{array}$ \\
\hline 100 & 1.548 & 27,3 & 21,68 \\
110 & 298 & 5,3 & 21,33 \\
120 & 136 & 2,4 & 19,83 \\
130 & 275 & 4,8 & 20,00 \\
140 & 122 & 2,1 & 20,71 \\
150 & 172 & 3,0 & 19,37 \\
160 & 64 & 1,1 & 26,02 \\
170 & 88 & 1,6 & 26,27 \\
180 & 199 & 3,5 & 22,26 \\
190 & 194 & 3,4 & 26,47 \\
200 & 1.265 & 22,3 & 29,04 \\
210 & 99 & 1,8 & 31,23 \\
220 & 561 & 9,9 & 26,26 \\
230 & 131 & 2,3 & 39,58 \\
240 & 79 & 1,4 & 18,00 \\
250 & 387 & 6,8 & 34,86 \\
280 & 8 & 0,1 & 34,78 \\
300 & 338 & $\mathbf{6 , 0}$ & 21,32 \\
310 & 148 & 2,6 & 20,64 \\
320 & 190 & 3,4 & 21,89 \\
400 & 1.053 & 18,6 & 28,77 \\
410 & 443 & 7,8 & 31,44 \\
420 & 231 & 4,1 & 28,21 \\
430 & 227 & 4,0 & 29,37 \\
& & &
\end{tabular}


(Continuación)

DISTRITO CENTRO

ESTRUCTURA COMERCIAL POR SUBSECTORES DE ACTIVIDAD

\begin{tabular}{|c|c|c|c|}
\hline \multirow{2}{*}{$\begin{array}{c}\text { SECTORES Y SUBSECTORES } \\
\text { DE ACTIVIDAD }\end{array}$} & \multirow[b]{2}{*}{$\begin{array}{c}\mathrm{N} .{ }^{\circ} \mathrm{DE} \\
\text { COMERCIOS }\end{array}$} & \multirow[b]{2}{*}{$\begin{array}{l}\% \text { COMERCIOS } \\
\text { DEL DISTRITO }\end{array}$} & \multirow[b]{2}{*}{$\begin{array}{c}\text { \% COMERCIOS DE } \\
\text { LA "ALMENDRA" }\end{array}$} \\
\hline & & & \\
\hline 490 & 152 & 2,7 & 23,42 \\
\hline 500 & 79 & 1,4 & 11,83 \\
\hline 600 & 11 & 0,2 & 19,30 \\
\hline 700 & 1.313 & 23,2 & 33,96 \\
\hline 710 & 15 & 0,3 & 26,79 \\
\hline 720 & 44 & 0,8 & 30,34 \\
\hline 730 & 139 & 2,4 & 26,99 \\
\hline 740 & 327 & 5,8 & 26,10 \\
\hline 750 & 255 & 4,5 & 43,00 \\
\hline 760 & 72 & 1,3 & 24,91 \\
\hline 770 & 69 & 1,2 & 21,77 \\
\hline 780 & 83 & 1,5 & 47,43 \\
\hline 790 & 309 & 5,4 & 59,08 \\
\hline 800 & 55 & 1,0 & 16,00 \\
\hline 810 & 29 & 0,5 & 18,01 \\
\hline 820 & 0 & 0,0 & 0,00 \\
\hline 830 & 0 & 0,0 & 0,00 \\
\hline 840 & 0 & 0,0 & 0,00 \\
\hline 850 & 3 & 0,1 & 44,44 \\
\hline 860 & 3 & 0,1 & 25,00 \\
\hline 870 & 8 & 0,1 & 15,09 \\
\hline 880 & 0 & 0,0 & 0,00 \\
\hline 890 & 12 & 0,2 & 41,38 \\
\hline TOTAL & 5.662 & 100,0 & 26,13 \\
\hline
\end{tabular}

Destacan, por este orden, los sectores de Confección, Mobiliario, Calzado y peletería, Librerías y papelerías, Otros productos no especificados dentro del grupo 700, Fruterias-Verdulerías y Joyerías-Relojerías.

En relación con la "almendra" y a nivel subsectorial, también destacan, por este orden, los subsectores Otros pruductos no especificados antes dentro del grupo 700, Bazares, Grandes Almacenes, Joyerías-Relojerías, Locales abiertos 24 horas, Camiserías-Lencerías, Calzado-Peletería, Productos textiles y de cuero sin predominio, Mobiliario, Textiles para el hogar y Muebles y equipos de Oficina. Todos ellos suponen más del $30 \%$ de los establecimientos de la "álmendra" de cada subsector. 


\section{COMERCIO MINORISTA POR BARRIOS}

La distribución espacial del comercio minorista en el distrito Centro no es homogénea. Destaca, en cuanto a número de comercios, el barrio de Embajadores con 1.588 establecimientos minoristas, que suponen el $28,0 \%$ del total de comercios del distrito. Frente a ello, el barrio de Cortes cuenta sólo con 488 tiendas, el $8,6 \%$ de las del distrito. Con valores intermedios están los barrios de Sol, Universidad y Justicia con 950, 945 y 934 comercios respectivamente y proporciones de $16,8,16,7$ y $16,5 \%$. Algo inferior es el número de establecimientos del barrio de Palacio: 757 , que suponen el $13,4 \%$ de los del distrito.

Los datos aquí expresados no reflejan el nivel de concentración comercial real de los barrios, como consecuencia de la diferencia superficial de los mismos: Sol, el barrio de menor tamaño, tiene 21,4 comercios por hectárea. Embajadores, 15,4 comercios por hectárea y Justicia, 15,3. Los barrios con menor densidad comercial son Palacio $(5,1)$, Cortes $(8,2)$ y Universidad $(9,2)$.

El área de concentración comercial mayor del distrito es, como en el siglo pasado, el centro del mismo: el entorno de la Puerta del Sol. Como áreas de concentración secundaria, pero muy importantes, destacan los barrios de Embajadores y Justicia.

El carácter de centro comercial viene dado efectivamente por el barrio de Sol, que destaca con 144,5 comercios por mil habitantes, valor muy por encima del resto de los barrios que componen el distrito. Justicia, el segundo barrio, tiene menos de la mitad $(60,7$ comercios por mil habitantes). Le siguen Cortes, con 46,7 comercios, Embajadores con 36,6, Palacio con 33,7 y Universidad con 32,0 comercios por mil habitantes

El cuadro 3 refleja las diferencias en la estructura comercial de los barrios que integran el distrito Centro.

Sol ocupa una posición central dentro del distrito. Es el barrio de menor superficie, población y densidad de habitantes. Sin embargo, es el segundo en número de comercios, sólo superado por Embajadores. En consecuencia, tiene un carácter eminentemente exportador, es decir, la mayor parte de los compradores proceden de fuera, ya sea de otro barrio, otro distrito de Madrid, de provincias o del extranjero.

En él conviven formas modernas de comercio con establecimientos tradicionales; el precio del suelo es muy elevado y existe en la mayor parte de su perímetro una intensa renovación comercial.

Dentro del barrio destaca un potente "centro comercial", con las características de los centros de las grandes ciudades. Se extiende desde 

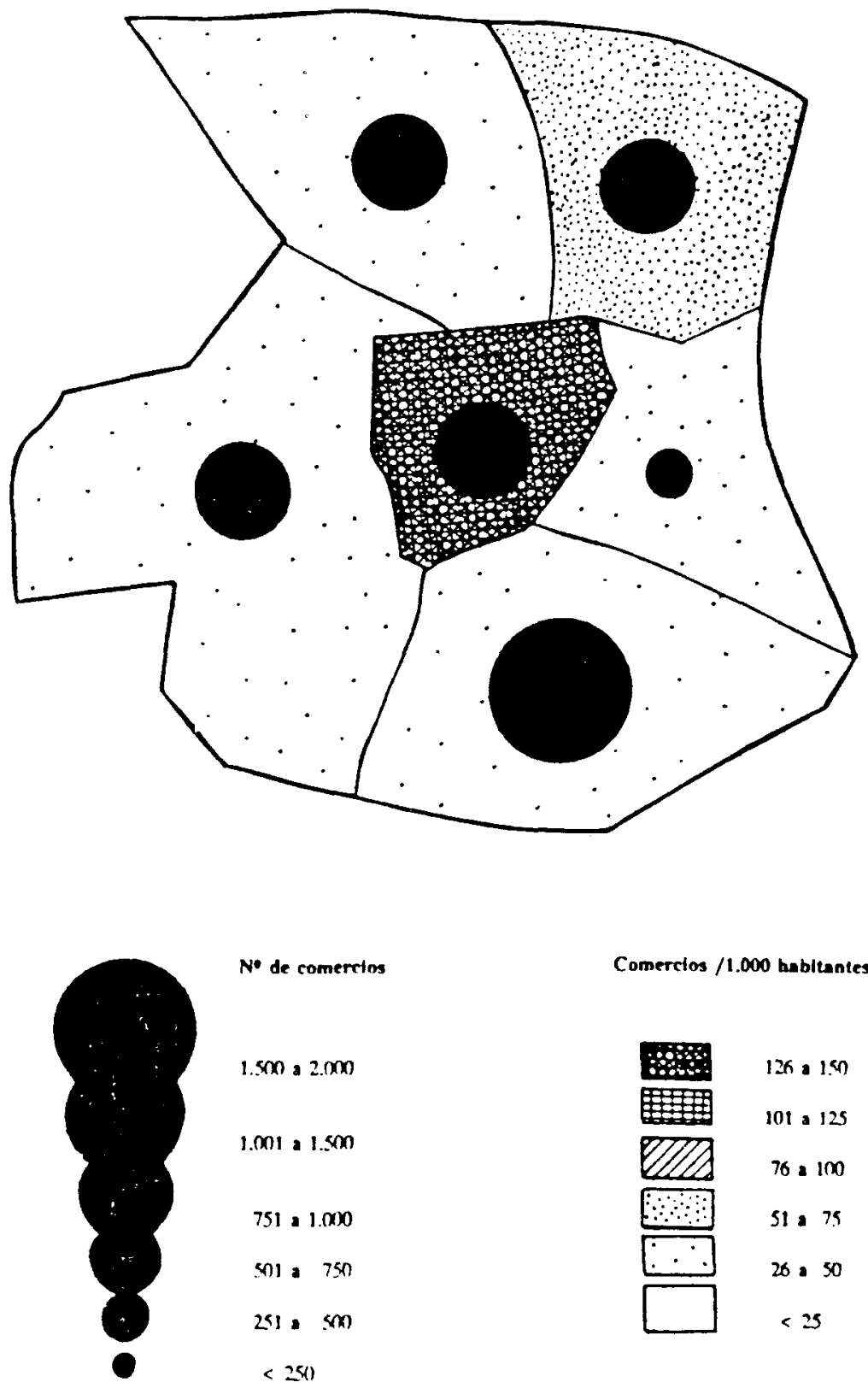

No de comerctos

Comeretos $/ 1.000$ habltantes

1.500 a 2.000

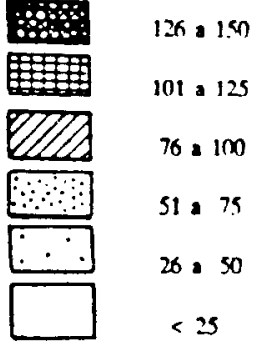

$251.5 m$

$<280$

Fig. 3. Volumen de establecimientos e indice de comercios por 1.000 habitantes. 
la Puerta del Sol hasta la Plaza de Callao y está constituido por dos Grandes Almacenes: "El Corte Inglés" y "Galerías Preciados", localizados en las calles Preciados y Carmen, respectivamente, el primero de ellos con un importante supermercado. Esta dotación se complementa con un gran número de comercios especializados. Se facilita la accesibilidad a estos establecimientos comerciales mediante calles peatonales.

Además de este "centro comercial", son característicos del barrio de Sol las galerías y los pasajes comerciales, de antigua tradición, que integran comercios especializados.

También son típicos del barrio los edificios residenciales ocupados parcialmente por comercios, que a veces conviven con oficinas $u$ otras actividades económicas. Asi, el edificio Mayor 4, que cuenta con un buen número de locales comerciales en las primeras plantas, destinados en su mayoria a librerias, papelerías y material didáctico.

La falta de suelo libre en el barrio hace que no se hayan podido instalar modernos Centros Comerciales; sin embargo antiguos edificios residenciales han sido reconvertidos, como los casos de Arenal 8 y el Centro Comercial Decomisos, este último de mayor antigüedad. Las calles especializadas son frecuentes, aunque algunas han decaído considerablemente.

En su estructura comercial Sol destaca por su fuerte especialización en los sectores Textil y Otros comercios. A nivel subsectorial, la Confección, Calzado, Peleterías, Joyerías-Relojerías, Otros especializados, Papelerías-Librerías, y Aparatos eléctricos y electrónicos, son las actividades más representadas.

Embajadores es, en relación con los barrios del distrito, el tercero en superficie y primero en población, densidad de habitantes y número de establecimientos comerciales. El territorio está constituido por los denominados "Barrios bajos" de Madrid, y continúa siendo un área eminentemente residencial y popular.

Tiene unas características propias y únicas. En él se encuentra el Rastro, con un tipo de comercio de compra-venta de toda clase de artículos y antigüedades, con predominio del sector mobiliario y en establecimientos, en un buen número de casos, de reducida superficie. Son frecuentes las calles especializadas en estos sectores de actividad, como también lo son las agrupaciones de anticuarios, almonedas y tiendas de muebles en galerías comerciales, de gran tradición y actividad en la zona.

Junto a este comercio tradicional y siguiendo la línea de especialización del Rastro en anticuarios, el antiguo Mercado Central de Pescados 

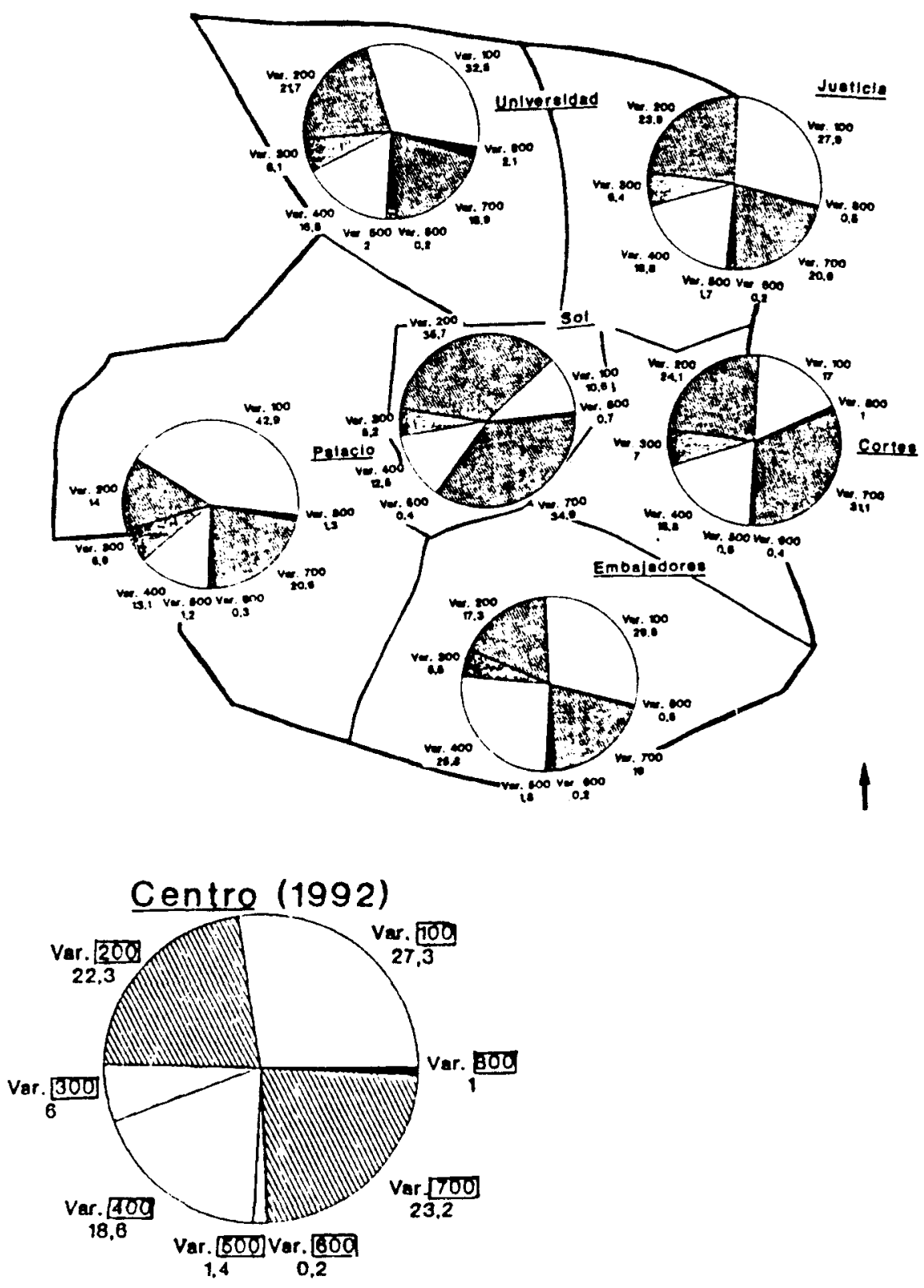

Fig. 4. Estructura sectorial de la actividad comercial en los barrios del distrito centro. 


\section{CUADRO 3. DISTRITO CENTRO. ESTABLECIMIENTOS COMERCIALES} POR BARRIOS Y SECTORES DE ACTIVIDAD

\begin{tabular}{|c|c|c|c|c|c|c|c|c|c|c|c|c|}
\hline & \multicolumn{4}{|c|}{ 1. CENTRO } & \multicolumn{4}{|c|}{1.1 PALACIO } & \multicolumn{4}{|c|}{1.2 ENBAJADORES } \\
\hline & A & $\mathbf{B}$ & C & $D$ & A & B & $\mathrm{c}$ & $D$ & A & $\mathbf{B}$ & $c$ & D \\
\hline 100 & 1548 & 12.12 & 27.34 & 100 & 325 & 14.49 & 42.93 & 20.99 & 473 & 10.91 & 29.79 & 30,56 \\
\hline 110 & 298 & 2.33 & 5.26 & 100 & 82 & 3.66 & 10.83 & 27.52 & 111 & 2.56 & 6.99 & 37.25 \\
\hline 120 & 136 & 1.06 & 2.40 & 100 & 30 & 1.34 & 3.96 & 22.06 & 42 & 0.97 & 2.64 & 30.88 \\
\hline 130 & 275 & 2.15 & 4.86 & 100 & 65 & 2.90 & 8.59 & 23.64 & 88 & 2.03 & 5.54 & 32.00 \\
\hline 140 & 122 & 0.96 & 2.15 & 100 & 34 & 1.52 & 4.49 & 27.87 & 41 & 0.95 & 2.58 & 33.61 \\
\hline 150 & 172 & 1.35 & 3.04 & 100 & 32 & 1.43 & 4.23 & 18.60 & 43 & 0.99 & 2.71 & 25,00 \\
\hline 160 & 64 & 0.50 & 9.13 & 100 & 11 & 0.49 & 1.45 & 17.19 & 18 & 0.42 & 1.13 & 28.13 \\
\hline 170 & 88 & 0.69 & 1.55 & 100 & 9 & 0.40 & 1.19 & 10.23 & 18 & 0.42 & 1.13 & 20.45 \\
\hline 180 & 199 & 1.56 & 3.51 & 100 & 33 & 1.47 & 4.36 & 16.58 & 56 & 1.29 & 3.53 & 28.14 \\
\hline 190 & 194 & 1.52 & 3.43 & 100 & 29 & 1.29 & 3.83 & 14.95 & 56 & 1.29 & 3.53 & 28.87 \\
\hline 200 & 1265 & 9.90 & 22.34 & 100 & 106 & 4.72 & 14.00 & 8.38 & 275 & 6.35 & 17.32 & 21.74 \\
\hline 210 & $9 \theta$ & 0.78 & 1.75 & 100 & 9 & 0.40 & 1.19 & 9.00 & 33 & 0.76 & 2.08 & 33.33 \\
\hline 220 & 561 & 4.39 & 9.91 & 100 & 35 & 1.56 & 4.62 & 6.24 & 127 & 2.93 & 8.00 & 22.64 \\
\hline 230 & 131 & 1.03 & 2.31 & 100 & 13 & 0.58 & 1.72 & 9.92 & 22 & 0.51 & 1.39 & 16.79 \\
\hline 240 & 79 & 0.62 & 1.40 & 100 & 12 & 0.53 & 1.59 & 15.19 & 16 & 0.37 & 1.01 & 20.25 \\
\hline 250 & 387 & 3.03 & 6.83 & 100 & 37 & 1.65 & 4.89 & 9.56 & 76 & 1.75 & 4.79 & 18.64 \\
\hline 280 & 8 & 0.08 & 0.14 & 100 & 0 & $0 . \infty$ & 0.00 & 0.00 & 1 & 0.02 & 0.08 & 12.50 \\
\hline 300 & 338 & 2.65 & 5.97 & 100 & 50 & 2.23 & 6.61 & 14.79 & 87 & 2.01 & 5.48 & 25.74 \\
\hline $\begin{array}{l}310 \\
320\end{array}$ & $\begin{array}{l}148 \\
190\end{array}$ & $\begin{array}{l}1.16 \\
1.49\end{array}$ & $\begin{array}{l}2.61 \\
3.36\end{array}$ & $\begin{array}{l}100 \\
100\end{array}$ & $\begin{array}{r}18 \\
131\end{array}$ & $\begin{array}{l}0.85 \\
1.38\end{array}$ & $\begin{array}{l}2.51 \\
4.10\end{array}$ & $\begin{array}{l}12.84 \\
16.32\end{array}$ & $\begin{array}{l}33 \\
54\end{array}$ & $\begin{array}{l}0.76 \\
1.25\end{array}$ & $\begin{array}{l}2.08 \\
3.40\end{array}$ & $\begin{array}{l}22.30 \\
28.42\end{array}$ \\
\hline 400 & 1053 & 8.24 & 18.59 & 100 & 99 & 4.41 & 1308 & 9.40 & 411 & 8.48 & 25.88 & 39.03 \\
\hline 410 & 443 & 3.47 & 7.82 & 100 & 32 & 1.43 & 4.23 & 7.22 & 225 & 5.19 & 14.17 & 50.79 \\
\hline 420 & 231 & 1.81 & 4.08 & 100 & 22 & 0.98 & 2.91 & 9.52 & 53 & 1.22 & 3.34 & 22.94 \\
\hline 430 & 227 & 1.78 & 4.01 & 100 & 31 & 1.38 & 4.10 & 13.66 & 54 & 1.25 & 3.40 & 23.79 \\
\hline 490 & 152 & 1.19 & 2.68 & 100 & 14 & 0.62 & 1.85 & 0.21 & 79 & 1.82 & 4.97 & 51.97 \\
\hline 500 & 79 & 0.62 & 1.40 & 100 & 9 & 0.40 & 1.19 & 11.39 & 28 & 0.65 & 1.76 & 35.44 \\
\hline 600 & 11 & 0.09 & 0.19 & 100 & 2 & 0.09 & 0.26 & 18.18 & 3 & 0.07 & 0.19 & 27.27 \\
\hline 700 & 1313 & .10 .28 & 23.19 & 100 & 156 & 6.95 & 20.61 & 11.88 & 302 & 6.97 & 19.02 & 23.00 \\
\hline 710 & 15 & 0.12 & 0.26 & 100 & 3 & 0.13 & 0.40 & 20.00 & 4 & 0.09 & 0.25 & 26.67 \\
\hline 720 & 44 & 0.34 & 0.78 & 100 & 8 & 0.36 & 1.06 & 18.18 & 8 & 0.18 & 0.50 & 18.18 \\
\hline 730 & 139 & 1.09 & 2.45 & 100 & 18 & 0.80 & 2.38 & 12.95 & 17 & 0.39 & 1.07 & 12.23 \\
\hline 740 & 327 & 2.56 & 5.77 & 100 & 48 & 2.14 & 6.34 & 14.68 & 49 & 1.13 & 3.09 & 14.98 \\
\hline 750 & 255 & 2.00 & 4.50 & 100 & 12 & 0.53 & 1.59 & 4.71 & 63 & 1.45 & 3.97 & 24.71 \\
\hline 760 & 72 & 0.56 & 1.27 & 100 & 10 & 0.45 & 1.32 & 13.89 & 28 & 0.65 & 1.76 & 38.89 \\
\hline 770 & 69 & 0.54 & 1.22 & 100 & 16 & 0.71 & 2.11 & 23.19 & 16 & 0.37 & 1.01 & 23.19 \\
\hline 780 & 83 & 0.65 & 1.47 & 100 & 3 & 0.13 & 0.40 & 3.61 & 25 & 0.58 & 1.57 & 30.12 \\
\hline 790 & 309 & 2.42 & 5.46 & 100 & 38 & 1.69 & 5.02 & 9.06 & 92 & 2.12 & 5.79 & 29.77 \\
\hline 800 & 55 & 0.44 & 0.89 & 100 & 10 & 0.45 & 1.32 & 17.86 & $\theta$ & 0.21 & 0.57 & 16.07 \\
\hline 810 & 29 & 0.23 & 0.51 & 100 & 6 & 0.27 & 0.79 & 20.69 & 4 & 0.09 & 0.25 & 13.97 \\
\hline 820 & 0 & 0.00 & 0.00 & 100 & 0 & 0.00 & 0.00 & 0.00 & 0 & 0.00 & 0.00 & 0.00 \\
\hline 830 & 0 & $0 . \infty 0$ & 0.00 & 100 & 0 & 0.00 & 0.00 & 0.00 & 0 & 0.00 & 0.00 & 0.00 \\
\hline 840 & 0 & 0.00 & 0.00 & 100 & 0 & 0.00 & 0.00 & $0 . \infty$ & 0 & 0.00 & 0.00 & 0.00 \\
\hline 850 & 3 & 0.03 & 0.07 & 100 & 0 & 0.00 & 0.00 & 0.00 & 0 & 0.00 & $0 . \infty$ & 0.00 \\
\hline 860 & 3 & 0.02 & 0.05 & 100 & 1 & 0.04 & 0.13 & 33.33 & 1 & 0.02 & 0.06 & 33.33 \\
\hline 870 & 8 & 0.06 & 0.14 & 100 & 1 & 0.04 & 0.13 & 12.50 & 3 & 0.07 & 0.19 & 37.50 \\
\hline 880 & 0 & 0.00 & $0 . \infty$ & 100 & 0 & 0.00 & 0.00 & 0.00 & 0 & 0.00 & 0.00 & 0.00 \\
\hline 890 & 12 & 0.09 & 0.21 & 100 & 2 & 0.09 & 0.26 & 16.67 & 1 & 0.02 & 0.06 & 8.33 \\
\hline TOTAL & 5662 & 44.34 & 100 & 100 & 757 & 33.74 & 100 & 13.37 & 1588 & 36.64 & 100 & 28.04 \\
\hline$\infty$ & 19 & 0.15 & & 100 & 3 & 0.13 & & 15.79 & 7 & 0.16 & & 36.84 \\
\hline
\end{tabular}

A: Numero de comercios. B: Número de comercios por 1.000 habitantes. C: $\%$ de comercios de cada actividad correspondiente a cada barrio o distrito. D: \% de comercios de cada actividad en cada barrio con relación al distrito. 
El comercio minorista en el centro de Madrid

\begin{tabular}{|c|c|c|c|c|c|c|c|c|c|c|c|c|}
\hline & \multicolumn{4}{|c|}{ 1. CENTRO } & \multicolumn{4}{|c|}{1.3 CORTES } & \multicolumn{4}{|c|}{1.4 JUSTICIA } \\
\hline & A & B & $c$ & D & A & $\mathrm{B}$ & C & $D$ & A & B & c & D \\
\hline 100 & 1548 & 12.12 & 27.34 & 100 & 83 & 7.95 & 17.01 & 5.36 & 260 & 16.91 & 27.84 & 16.80 \\
\hline 110 & 298 & 2.33 & 5.26 & 100 & 6 & 0.57 & 1.23 & 2.01 & 41 & 2.67 & 4.39 & 13.76 \\
\hline 120 & 136 & 1.06 & 2.40 & 100 & 4 & 0.38 & 0.82 & 2.94 & 26 & 1.69 & 2.78 & 19.12 \\
\hline 130 & 275 & 2.15 & 4.86 & 100 & 6 & 0.57 & 1.23 & 2.18 & 58 & 3.77 & 6.21 & 21.09 \\
\hline 140 & 122 & 0.96 & 2.15 & 100 & 2 & 0.19 & 0.41 & 1.64 & 22 & 1.43 & 2.36 & 18.03 \\
\hline 150 & 172 & 1.35 & 3.04 & 100 & 15 & 1.44 & 3.07 & 8.72 & 30 & 1.95 & 3.21 & 17.44 \\
\hline 160 & 64 & 0.50 & 1.13 & 100 & 9 & 0.86 & 1.84 & 14.06 & 9 & 0.59 & 0.96 & 14.06 \\
\hline 170 & 88 & 0.69 & 1.55 & 100 & 11 & 1.05 & 2.25 & 12.50 & 10 & 0.65 & 1.07 & 11.36 \\
\hline 180 & 199 & 1.56 & 3.51 & 100 & 14 & 1,34 & 2.87 & 7.04 & 30 & 1.85 & 3.21 & 15.08 \\
\hline 190 & 194 & 1.52 & 3.43 & 100 & 16 & 1.53 & 3.28 & 8.25 & 34 & 2.21 & 3.64 & 17.53 \\
\hline 200 & 1265 & 9.90 & 22.34 & 100 & $\uparrow 17$ & 11.21 & 23.98 & 9.25 & 223 & 14.50 & 23.88 & 17.63 \\
\hline 210 & 99 & 0.78 & 1.75 & 100 & 11 & 1.05 & 2.25 & 11.11 & 9 & 0.59 & 0.96 & 9.09 \\
\hline 220 & 561 & 4.39 & 9.91 & 100 & 48 & 4.60 & 9.84 & 8.56 & 115 & 7.48 & 12.31 & 20.50 \\
\hline 230 & 131 & 1.03 & 2.31 & 100 & 20 & 1.92 & 4.10 & 15.27 & 19 & 1.24 & 2.03 & 14.50 \\
\hline 240 & 79 & 0.62 & 1.40 & 100 & 2 & 0.19 & 0.41 & 2.53 & 11 & 0.72 & 1.18 & 13.92 \\
\hline 250 & 387 & 3.03 & 6.63 & 100 & 36 & 3.45 & 7.38 & 9.30 & 67 & 4.36 & 7.17 & 17.31 \\
\hline 280 & 8 & 0.06 & 0.14 & 100 & 0 & 0.00 & 0.00 & $0 . \infty 0$ & 2 & 0.13 & 0.21 & 25.00 \\
\hline 300 & 338 & 2.65 & 5.97 & 100 & 34 & 3.26 & 6.97 & 10.06 & 60 & 3.90 & 6.42 & 17.75 \\
\hline $\begin{array}{l}310 \\
320\end{array}$ & $\begin{array}{l}148 \\
190\end{array}$ & $\begin{array}{l}1.16 \\
1.49\end{array}$ & $\begin{array}{l}2.61 \\
3.36\end{array}$ & $\begin{array}{l}100 \\
100\end{array}$ & $\begin{array}{l}17 \\
17\end{array}$ & $\begin{array}{l}1.63 \\
1.63\end{array}$ & $\begin{array}{l}3.48 \\
3.48\end{array}$ & $\begin{array}{c}11.49 \\
8.95\end{array}$ & $\begin{array}{l}29 \\
31\end{array}$ & $\begin{array}{l}1.89 \\
2.02\end{array}$ & $\begin{array}{l}3.10 \\
3.32\end{array}$ & $\begin{array}{l}19.95 \\
16.32\end{array}$ \\
\hline 400 & 1053 & 8.24 & 18.59 & 100 & 92 & 8.81 & 18.85 & 8.74 & 178 & 11.44 & 18.84 & 16.71 \\
\hline 410 & 443 & 3.47 & 7.82 & 100 & 46 & 4.41 & 9.43 & 10.37 & 74 & 4.81 & 7.92 & 16.70 \\
\hline 420 & 231 & 1.81 & 4.08 & 100 & 14 & 1.34 & 2.87 & 6.06 & 58 & 3.77 & 6.21 & 25.11 \\
\hline 430 & 227 & 1.78 & 4.01 & 100 & 23 & 2.20 & 4.71 & 10.13 & 26 & 1.69 & 2.78 & 11,45 \\
\hline 490 & 152 & 1.19 & 2.68 & 100 & 8 & 0.86 & 1.84 & 5.92 & 18 & 1.17 & 1.93 & 11.84 \\
\hline 500 & 79 & 0.62 & 1.40 & 100 & 3 & 0.29 & 0.61 & 3.80 & 16 & 1.04 & 1.71 & 20.25 \\
\hline 600 & 11 & 0.09 & 0.19 & 100 & 2 & 0.19 & 0.41 & 18.18 & 2 & 0.13 & 0.21 & 18.18 \\
\hline 700 & 1313 & 10.28 & 23.18 & 100 & 152 & 14.56 & 31.15 & 11.58 & 192 & 12,48 & 20.56 & 14.62 \\
\hline 740 & 15 & 0.12 & 0.26 & 100 & 3 & 0.29 & 0.61 & $20 . \infty$ & 2 & 0.13 & 0.21 & 13.33 \\
\hline 720 & 44 & 0.34 & 0.78 & 100 & 1 & 0.10 & 0.20 & 2.27 & 18 & 1.17 & 1.93 & 40.91 \\
\hline 730 & 139 & 1.00 & 2.45 & 100 & 20 & 1.92 & 4.10 & 14.39 & 27 & 1.76 & 2.89 & 19.42 \\
\hline 740 & 327 & 2.56 & 5.77 & 100 & 53 & 5.08 & 10.86 & 16.21 & 48 & 3.12 & 5.14 & 14.68 \\
\hline 750 & 255 & 2.00 & 4.50 & 100 & 28 & 2.68 & 5.74 & 10.98 & 31 & 2.02 & 3.32 & 12.16 \\
\hline 760 & 72 & 0.56 & 1.27 & 100 & 1 & 0.10 & 0.20 & 1.39 & 9 & 0.59 & 0.96 & 12.50 \\
\hline 770 & 69 & 0.54 & 1.22 & 100 & 9 & 0.86 & 1.84 & 13.04 & 16 & 1.04 & 1.71 & 23.19 \\
\hline 780 & 83 & 0.65 & 1.47 & 100 & 2 & 0.19 & 0.41 & 2.41 & 8 & 0.52 & 0.86 & 9.64 \\
\hline 790 & 309 & 2.42 & 5.46 & 100 & 35 & 3.35 & 7.17 & 11.33 & 33 & 2.15 & 3.53 & 10.68 \\
\hline 800 & 55 & 0.44 & 0.99 & 100 & 5 & 0.48 & 1.02 & 8.93 & 5 & 0.33 & 0.54 & 8.93 \\
\hline 810 & 29 & 0.23 & 0.51 & 100 & 3 & 0.29 & 0.61 & 10.34 & 1 & 0.07 & 0.11 & 3.45 \\
\hline 820 & 0 & 0.00 & 0.00 & 100 & 0 & 0.00 & 0.00 & 0.00 & 0 & 0.00 & $0 . \infty$ & 0.00 \\
\hline 830 & 0 & 0.00 & 0.00 & 100 & 0 & 0.00 & 0.00 & 0.00 & 0 & 0.00 & 0.00 & 0.00 \\
\hline 840 & 0 & 0.00 & 0.00 & 100 & 0 & 0.00 & 0.00 & 0.00 & 0 & 0.00 & $0 . \infty$ & 0.00 \\
\hline 850 & 3 & 0.03 & 0.07 & 100 & 0 & $0 . \infty$ & 0.00 & 0.00 & 0 & 0.00 & 0.00 & 0.00 \\
\hline 860 & 3 & 0.02 & 0.05 & 100 & 0 & 0.00 & $0 . \infty$ & $0 . \infty$ & 0 & 0.00 & 0.00 & 0.00 \\
\hline 870 & 8 & 0.06 & 0.14 & 100 & 1 & 0.10 & 0.20 & 12.50 & 2 & 0.13 & 0.21 & 25.00 \\
\hline 880 & 0 & 0.00 & 0.00 & 100 & 0 & 0.00 & 0.00 & 0.00 & 0 & 0.00 & 0.00 & 0.00 \\
\hline 890 & 12 & 0.09 & 0.21 & 100 & 1 & 0.10 & 0.20 & 8.33 & 2 & 0.13 & 0.21 & 16.67 \\
\hline TOTAL & 5662 & 44.34 & 100 & 100 & 488 & 46.74 & 100 & 8.62 & 934 & 60.73 & 100 & 16.49 \\
\hline$\infty 00$ & 19 & 0.15 & & 100 & 1 & 0.10 & & 5.26 & 3 & 0.20 & & 15.79 \\
\hline
\end{tabular}

A: Numero de comercios. B: Número de comercios por 1.000 habitantes. C: $\%$ de comercios de cada actividad correspondiente a cada barrio o distrito. D: \% de comercios de cada actividad en cada barrio con relación al distrito. 


\begin{tabular}{|c|c|c|c|c|c|c|c|c|c|c|c|c|}
\hline & \multicolumn{4}{|c|}{ 1. CENTRO } & \multicolumn{4}{|c|}{1.5 UNIVERSIOAD } & \multicolumn{4}{|c|}{$1.6 \mathrm{SOL}$} \\
\hline & A & $B$ & C & $D$ & A & B & c & 0 & A & B & C & D \\
\hline 100 & 1548 & 12.12 & 27.34 & 100 & 307 & 10.39 & 32.45 & 18.83 & 100 & 15.21 & 10.53 & 6.46 \\
\hline 110 & 298 & 2.33 & 5.26 & 100 & 52 & 1.76 & 5.50 & 17.45 & 6 & 0.81 & 0.63 & 2.01 \\
\hline 120 & 136 & 1.06 & 2,40 & 100 & 27 & 0.91 & 2.85 & 19.85 & 7 & 1.06 & 0.74 & 5.15 \\
\hline 130 & 275 & 2.15 & 4.86 & 100 & 49 & 1.66 & 5.18 & 17.82 & 9 & 1.37 & 0.95 & 3.27 \\
\hline 140 & 122 & 0.96 & 2.15 & 100 & 22 & 0.74 & 2.33 & 18.03 & 1 & 0.15 & 0.11 & 0.82 \\
\hline 150 & 172 & 1.35 & 3.04 & 100 & 31 & 1.05 & 3.28 & 18.02 & 21 & 3.19 & 2.21 & 12.21 \\
\hline 160 & 64 & 0.50 & 1.13 & 100 & 16 & 0.54 & 1.69 & $25 . \infty 0$ & 1 & 0.15 & 0.11 & 1.56 \\
\hline 170 & 88 & 0.69 & 1.55 & 100 & 19 & 0.64 & 2.01 & 21.50 & 21 & 3.19 & 2.21 & 23.86 \\
\hline 180 & 199 & 1.56 & 3.51 & 100 & 55 & 1.86 & 5,81 & 27.64 & 11 & 1,67 & 1.16 & 5.53 \\
\hline 190 & 194 & 1.52 & 3.43 & 100 & 36 & 1.22 & 3.81 & 18.56 & 23 & 3.50 & 2.42 & 11.86 \\
\hline 200 & 1285 & 9.90 & 22.34 & 100 & 205 & 6.94 & 21.67 & 16.21 & 339 & 51.57 & 35.68 & 26.80 \\
\hline 210 & 99 & 0.78 & 1.75 & 100 & 14 & 0.47 & 1.48 & 14.14 & 23 & 3.50 & 2.42 & 23.23 \\
\hline 220 & 581 & 4.39 & 9.91 & 100 & 78 & 2.67 & 8.35 & 14.08 & 157 & 23.89 & 16.53 & 27.90 \\
\hline 230 & 131 & 1.03 & 2.31 & 100 & 20 & 0.68 & 2.11 & 15.27 & 37 & 5.63 & 3.89 & 28.24 \\
\hline 240 & 79 & 0.62 & 1.40 & 100 & 21 & 0.71 & 2.22 & 26.58 & 17 & 2.50 & 1.79 & 21.52 \\
\hline 250 & 387 & 3.03 & 8.83 & 100 & 68 & 2.30 & 3.19 & 17.57 & 103 & 15.67 & 10.84 & 6.81 \\
\hline 280 & $\mathbf{B}$ & 0.08 & 0.14 & 100 & 3 & 0.10 & 0.32 & 37.50 & 2 & 0.30 & 0.21 & 25.00 \\
\hline 300 & 338 & 2.65 & 5.97 & 100 & 58 & 1.96 & 6.13 & 17,16 & 49 & 7.45 & 5.16 & 14.20 \\
\hline $\begin{array}{l}310 \\
320\end{array}$ & $\begin{array}{l}148 \\
190\end{array}$ & $\begin{array}{l}1.16 \\
1.49\end{array}$ & $\begin{array}{l}2.61 \\
3.36\end{array}$ & $\begin{array}{l}100 \\
100\end{array}$ & $\begin{array}{l}30 \\
28\end{array}$ & $\begin{array}{l}1.02 \\
0.95\end{array}$ & $\begin{array}{l}3.17 \\
2.96\end{array}$ & $\begin{array}{r}8.88 \\
14.74\end{array}$ & $\begin{array}{l}20 \\
29\end{array}$ & $\begin{array}{l}3.04 \\
4.41\end{array}$ & $\begin{array}{l}2.11 \\
3.05\end{array}$ & $\begin{array}{c}5.82 \\
15.23\end{array}$ \\
\hline 400 & 1053 & 8.24 & 18.59 & 100 & 156 & 5.28 & 16.49 & 14.81 & 118 & 18.10 & 12.53 & 11.30 \\
\hline 410 & 443 & 3.47 & 7.82 & 100 & 47 & 1.59 & 4.97 & 10.61 & 19 & 2.89 & 2.00 & 4.28 \\
\hline 420 & 231 & 1.81 & 4.08 & 100 & 36 & 1.22 & 3.81 & 15.58 & 48 & 7.30 & 5.05 & 20.78 \\
\hline 430 & 227 & 1.78 & 4.01 & 100 & 46 & 1.56 & 4.86 & 20.26 & 47 & 7.15 & 4.95 & 20.70 \\
\hline 490 & 152 & 1.19 & 2.68 & 100 & 27 & 0.91 & 2.85 & 17.76 & 5 & 0.76 & 0.53 & 3.29 \\
\hline 500 & 79 & 0.62 & 1.40 & 100 & 19 & 0.64 & 2.01 & 24.05 & 4 & 0.61 & 0.42 & 5.08 \\
\hline 600 & 11 & 0.09 & 0.19 & 100 & 2 & 0.07 & 0.21 & 18.18 & 0 & 0.00 & $0 . \infty$ & 0.00 \\
\hline 700 & 1313 & 10.28 & 23.19 & 100 & 179 & 6.06 & 18.92 & 13.63 & 332 & 50.51 & 34.95 & 26.29 \\
\hline 710 & 15 & 0.12 & 0.26 & 100 & 2 & 0.07 & 0.21 & 13.33 & 1 & 0.15 & 0.11 & 6.87 \\
\hline 720 & 44 & 0.34 & 0.78 & 100 & 6 & 0.20 & 0.63 & 13.64 & 3 & 0.46 & 0.32 & 6.82 \\
\hline 730 & 139 & 1.00 & 2.45 & 100 & 17 & 0.58 & 1.80 & 12.23 & 40 & 6.09 & 4.21 & 28.78 \\
\hline 740 & 327 & 2.56 & 5.77 & 100 & 68 & 2.30 & 7.19 & 20.80 & 61 & 9.28 & 6.42 & 18.65 \\
\hline 750 & 255 & 2.00 & 4.50 & 100 & 26 & 0.88 & 2.75 & 10.20 & 95 & 14.45 & 10.00 & 37.25 \\
\hline 760 & 72 & 0.56 & 1.27 & 100 & 12 & 0.41 & 1.27 & 16.67 & 12 & 1.83 & 1.26 & 16.67 \\
\hline 770 & 69 & 0.54 & 1.22 & 100 & 7 & 0.24 & 0.74 & 10.14 & 5 & 0.76 & 0.53 & 7.25 \\
\hline 780 & 83 & 0.65 & 1.47 & 100 & 7 & 0.24 & 0.74 & 8.43 & 38 & 5.78 & 4.00 & 45.78 \\
\hline 790 & 309 & 2.42 & 5.46 & 100 & 34 & 1.15 & 3.59 & $11 . \infty$ & 77 & 11.71 & 8.11 & 24.92 \\
\hline 800 & 55 & 0.44 & 0.99 & 100 & 19 & 0.68 & 2.11 & 35.71 & 7 & 1.06 & 0.74 & 12.50 \\
\hline 810 & 29 & 0.23 & 0.51 & 100 & 13 & 0.44 & 1.37 & 44.83 & 2 & 0.30 & 0.21 & 6.90 \\
\hline 820 & 0 & 0.00 & 0.00 & 100 & 0 & 0.00 & 0.00 & 0.00 & 0 & $0 . \infty$ & 0.00 & 0.00 \\
\hline 830 & 0 & $0 . \infty$ & 0.00 & 100 & 0 & 0.00 & 0.00 & 0.00 & 0 & 0.00 & $0 . \infty$ & 0.00 \\
\hline 840 & 0 & 0.00 & 0.00 & 100 & 0 & 0.00 & 0.00 & 0.00 & 0 & 0.00 & 0.00 & 0.00 \\
\hline 850 & 3 & 0.03 & 0.07 & 100 & 1 & 0.07 & 0.21 & 50.00 & 2 & 0.30 & 0.21 & 50.00 \\
\hline 860 & 3 & 0.02 & 0.05 & 100 & 1 & 0.03 & 0.11 & 33.33 & 0 & 0.00 & 0.00 & 0.00 \\
\hline 870 & 8 & 0.06 & 0.14 & 100 & 1 & 0.03 & 0.11 & 12.50 & 0 & 0.00 & $0 . \infty$ & 0.00 \\
\hline 880 & 0 & 0.00 & 0.00 & 100 & 0 & 0.00 & $0 . \infty$ & 0.00 & 0 & 0.00 & 0.00 & 0.00 \\
\hline 890 & 12 & 0.09 & 0.21 & 100 & 3 & 0.10 & 0.32 & 25.00 & 3 & 0.46 & 0.32 & 25.00 \\
\hline TOTAL & 5662 & 44.34 & 100 & 100 & 945 & 32.01 & 100 & 18.70 & 950 & 144.53 & 100 & 16.78 \\
\hline 000 & 19 & 0.15 & & 100 & 1 & 0.03 & & 15.79 & 4 & 0.61 & & 21.05 \\
\hline
\end{tabular}

A: Numero de comercios. B: Número de comercios por 1.000 habitantes. C: $\%$ de comercios de cada actividad correspondiente a cada barrio o distrito. D: \% de comercios de cada actividad en cada barrio con relación al distrito. 
de Madrid, localizado en el barrio, ha sido rehabilitado y transformado en un moderno Centro Comercial de venta de antigüedades y productos de autor en 1988, bajo la denominación de "Mercado Puerta de Toledo". La importante oferta de anticuarios de este centro refuerza la especialización de Embajadores en el sector, aunque su carácter, marcadamente elitista, ofrece un fuerte contraste con los establecimientos del Rastro.

Existe también a nivel de barrio una cierta especialización en el sector del automóvil -recambios y accesorios fundamentalmente- en pequeños establecimientos localizados en la porción más meridional del Rastro y en el límite sur del barrio. En la línea marcada por las Rondas de Atocha, Valencia y Toledo y la plaza del Campillo del Mundo Nuevo, los establecimientos del sector tienen en general una mayor superficie y se dedican, algunos de ellos, a la venta de vehículos.

Es importante destacar la transformación experimentada en los últimos años en Embajadores, en relación con la expansión del comercio mayorista, en detrimento del minorista.

Tradicionalmete existía una pequeña zona de comercio mayorista en las proximidades de la plaza de Tirso de Molina. Actualmente la zona mayorista comprende desde la calle Toledo al oeste, hasta la calle de Atocha al este, extendiéndose por la cabecera del Rastro y la porción más septentrional de Lavapiés. Los sectores de actividad más destacados son diseño-moda, bazares y artículos eléctricos y electrónicos, complementos del vestido, artículos de cuero, bisutería y lencería.

Existe un fuerte contraste entre los establecimientos situados en las proximidades de la plaza Tirso de Molina y en los ejes más importantes, y los localizados al sur de la plaza. El entorno de ésta se ha convertido en el lugar de concentración de mayoristas de diseño-moda más importante de Madrid. En la propia plaza, el antiguo edificio de los Almacenes Progreso es hoy "Madrid Fusión", centro donde 45 fabricantes españoles y extranjeros de prêt a porter se agrupan en seis pisos. Centros comerciales menores pero de idénticas características, se localizan en las calles Concepción Jerónima y Conde de Romanones.

En contraposición, al sur de la plaza de Tirso de Molina el comercio mayorista de confección tiene un carácter más popular, con productos de baja calidad. La confección se combina con complementos y bazares de "baratillo". Se trata en conjunto de un tipo de comercio donde se surten los vendedores ambulantes, gitanos e inmigrantes extranjeros en su mayoría.

Por grupos de actividad destaca en el barrio de Embajadores el sector de Alimentación y dentro de él el subsector Frutas, verduras y hortalizas. 
Este predominio se debe a la existencia de dos mercados: el de Antón Martín, en la calle Santa Isabel, con 144 puestos, de los que 123 corresponden al sector alimentación ( $M{ }^{\circ}$ Economía y Hacienda, 1989), y el de San Fernando en la calle de Embajadores, con 140 puestos, 112 de ellos de alimentación (ibid.). Esta dotación comercial de artículos de primera necesidad se complementa con los 37 puestos de la única Galería de Alimentación del distrito, situada en la calle Toledo 109. (Ayuntamiento de Madrid, 1987)

La importante oferta de establecimientos alimenticios en el barrio, en función sobre todo de su comercio agrupado, está en relación con su volumen de población: no olvidemos que se trata de un barrio fundamentalmente residencial, donde vive una tercera parte de la población del Centro y donde no ha tenido lugar el proceso de conversión del espacio residencial en oficinas y servicios, general en el resto del distrito.

El sector Equipamiento del Hogar ocupa el segundo lugar en la estructura comercial del barrio. El tipo de comercio del Rastro - mobiliario, anticuarios y chamarilerías - lo justifica. Otro Comerico al por menor y el sector Textil destacan en tercer y cuarto lugares.

El barrio cuenta con un Almacén Popular, "Simago», en la calle Valencia 2, próximo a la plaza de Lavapiés, donde se organiza un nodo comecial secundario dentro del barrio de Embajadores.

Justicia es el cuarto barrio en superficie, población y número de comercios y el tercero en densidad de población. Tiene una densidad de comercios por hectárea próxima al barrio de Embajadores y un índice de comercios por mil habitantes superior a Cortes, Embajadores, Palacio y Universidad.

Su importancia comercial viene dada principalmente por el sector de Alimentación, con dos mercados: el de Barceló, remodelado recientemente, con la nueva denominación de Centro Comercial Barceló, tiene 173 puestos, de los que 150 son de alimentación. Y el de San Antón, en la calle Augusto Figueroa, con 254 puestos de los que 252 son de alimentación. (M. ${ }^{\circ}$ de Economía y Hacienda, 1989).

Fuera del sector de Alimentación, los más representados son: el sector Textil, y secundariamente Otros comercios al por menor y Equipamiento del Hogar.

Las calles de Hortaleza y Fuencarral, ejes comerciales tradicionales del barrio, han visto decaer su importacia al compás del deterioro urbano de la zona. La tradicional especialización de la calle Fuencarral en Peleterías y Zapaterías ha disminuido considerablemente en favor de comercios de confección de tipo popular, y para jóvenes. 
Sin embargo, algunas especializaciones a nivel de calle subsisten e incluso en los últimos años se han reforzado: es el caso de los establecimientos dedicados a bellas artes de la calle Hortaleza. Lo mismo ocurre con la calle Barquillo en el sector electrónico, con continua apertura de nuevos establecimientos del sector, junto a los tradicionales.

En los últimos años se observan nuevas especializaciones y una nueva vitalidad en algunas calles localizadas en el sector norte del barrio, donde se abren comercios, algunos de lujo: Galerías de Arte en la calle Argensola, comercios de diseño-moda en la calle Almirante, muestrarios de calzado en Augusto Figueroa.

Dentro de esta línea de especialización y renovación no podían faltar tipos nuevos de comercios como los de Todo a 100 pesetas, de los que existe una buena muestra en el principio de la calle Hortaleza, junto a la Gran Vía. Esta última calle sigue siendo uno de los ejes comerciales de mayor calidad del barrio.

Universidad ocupa el segundo lugar en extensión, población y densidad de la misma y el tercero en número de comercios.

Como barrio residencial, destaca en él el sector Alimentación, con abundancia de establecimientos de puerta de calle, si bien existe un mercado de abastos - el de Los Mostenses-que justifica el predominio de los establecimientos de primera necesidad. Se localiza en la plaza de los Mostenses, junto a la Gran Vía y cuenta con 265 puestos, de los que 230 son de Alimentación. (M. ${ }^{\circ}$ Economía y Hacienda, 1989)

Fuera de este sector comercial, destacan, aunque a gran distancia, los de Textil, Otro comercio al por menor y Equipamiento del Hogar.

A nivel comercial es un barrio de grandes contrastes, con calles de comercio muy popular, como son fundamentalmente las Correderas Alta y Baja de San Pablo y la calle del Espíritu Santo, donde existe un predominio de tiendas de alimentación; frente a calles con un comercio más selecto, como la Gran Vía, Sagasta y Carranza. Engloba el barrio calles de tradición comercial como Fuencarral, San Bernardo y Pez, ésta en proceso de transformación. Cuenta también con varias calles especializadas.

Junto a este comercio tradicional, hay que destacar la existencia de un Gran Almacén, -El Corte Inglés de Princesa- punta de lanza de un importante "centro comercial», que se extiende por los barrios limitrofes, dentro de los distritos de Moncloa y Chamberi, en los que se desarrolla gran actividad comercial, tanto en establecimientos especializados, como en nuevos Centros Comerciales - “El Laurel de Princesa", "Galaxia" y "Centro Argüelles»-. 
En el extremo opuesto del barrio destaca el Almacén Popular "SEPU», en la Gran Vía, que prolonga el centro comercial de Sol.

Cortes ocupa el quinto lugar en superficie, población y densidad de la misma. En número de comercios es el cuarto.

El sector comercial más importante en el barrio es Otro comercio al por menor, seguido de Textil, Equipamiento del Hogar y en cuarto lugar Alimentación, donde destaca el comercio especializado, y las panaderíaspastelerías.

La poca importacia del sector Alimentación dentro de la estructura comercial del barrio se explica por la ausencia de Mercados y Galerías de alimentación, dada la escasa población residente. Hay que tener en cuenta que una gran proporción de superficie del barrio es de propiedad institucional y está dedicada a usos no residenciales: Organismos oficiales, Bancos, Iglesias, Teatros, Hoteles, etc. que se sitúan, sobre todo, en las proximidades del $\mathrm{P} .{ }^{\circ}$ del Prado, calle Alcalá y Carrera de San Jerónimo.

El comercio se localiza preferentemente en las proximidades de los barrios limítrofes de Sol y Embajadores, a lo largo de las calles de Atocha, de la Cruz, del Príncipe, y como ejes interiores las calles del León y del Prado. Esta última, especializada tradicionalmente en antigüedades junto con la calle de Santa Catalina, ha decaído algo en los últimos años.

Destacan algunas pequeñas agrupaciones comerciales, como la Galería comercial Sevilla, en el paso subterráneo de la plaza de Canalejas y el pasaje comercial de Núñez de Arce.

Como exponente máximo de la renovación comercial de la zona, ha surgido en los últimos años el Centro Comercial elitista "La Galería del Prado» en los bajos del Hotel Palace, dirigido a una clientela compuesta por turistas extranjeros, viajeros residentes en el Hotel, empleados de los distintos organismos localizados en la zona y población del vecino barrio de los Jerónimos.

Palacio es el barrio de mayor superficie, tercero en población y penúltimo en densidad de la misma y en número de comercios, dentro del distrito Centro.

Se caracteriza por la supervivencia de comercios antiguos especializados: tonelerías, cererías, cordelerías, esparterías, tiendas de sacos, cedacerías, boterías, todas ellas en franca regresión, localizadas en el área urbana más antigua de Madrid, que se prolonga hacia el barrio de Sol. Los comercios que desaparecen son sucedidos con frecuencia por mesones, restaurantes o tabernas típicas, en función del turismo que visita la zona. 
El predominio absoluto es de establecimientos del sector Alimentación, con el $42,9 \%$ del total de su dotación comercial. En este predomino tienen destacado papel los mercados de La Cebada y San Miguel. El primero, totalmente transformado, ya que fue sustituido el viejo recinto de hierro por otro de ladrillo y cemento, se localiza en la plaza de La Cebada y tiene 250 puestos, todos ellos de Alimentación ( $M .^{\circ}$ de Economía y Hacienda, 1989). El mercado de San Miguel es el único de hierro que subsiste; tiene 74 puestos, todos ellos de alimentación. La existencia de estos dos Mercados y el reducido volumen de comercios del barrio explican el fuerte peso del subsector Frutas, verduras y hortalizas.

Fuera del sector Alimentación y a gran distancia, destacan los sectores Otro comercio al por menor, Textil y Equipamiento del Hogar.

Las áreas más comerciales son las localizadas junto al Rastro, en las proximidades del barrio de Sol, y los entornos de los Mercados. Los ejes más destacados son las calles Toledo, Mayor y la Gran Vía. No faltan algunas calles especializadas.

\section{CALLES COMERCIALES}

Existen en el distrito Centro 434 calles que tienen al menos un establecimiento comercial. Sin embargo, la mayoría posee un reducido número de comercios. El cuadro 4 refleja la distribución de frecuencias según el número de comercios por calle.

CUADRO 4. DISTRITO CENTRO. CALLES Y PLAZAS SEGÚN NÚMERO DE COMERCIOS

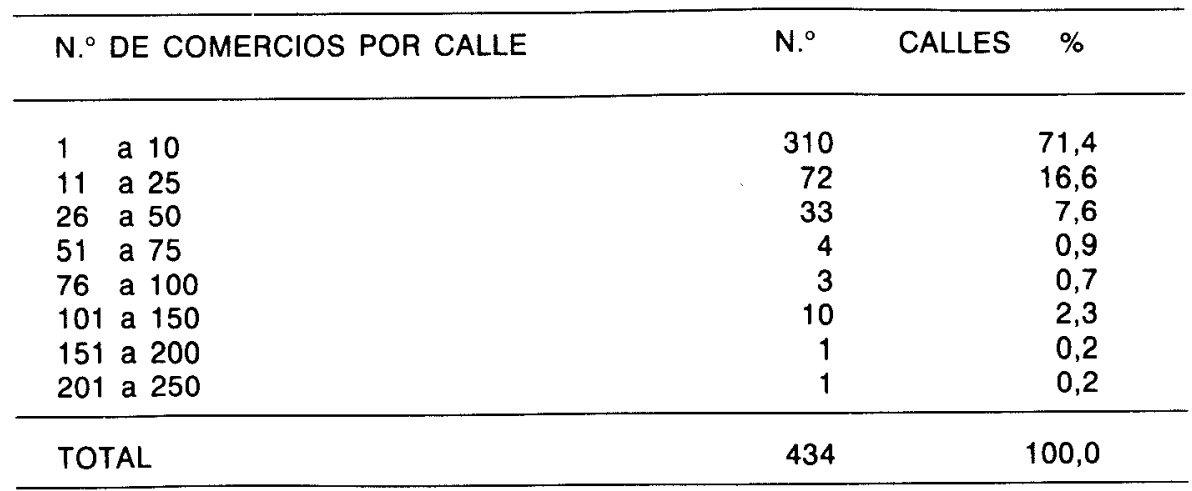

Fuente: Trabajo de campo. Elaboración propia. 
Como se observa, más del $70 \%$ de las calles y plazas del barrio tienen entre 1 y 10 comercios, no pudiéndose considerar como calles comerciales. En el extremo opuesto, un reducido número de calles posee una gran cantidad de comercios.

Tomando en consideración únicamente las calles y plazas que cuentan con 50 comercios y más, 21 de ellas concentran un volumen de 2.294 establecimientos. En cifras relativas, el $4,8 \%$ del callejero concentra el $40,5 \%$ del total de establecimientos comerciales del distrito.

El cuadro 5 recoge la relación de calles según el número total de comercios a partir de 50 y en orden decreciente.

Las calles que concentran mayor número de comercios son, bien las calles comerciales más largas, bien las que cuentan con algún Mercado: así la plaza de la Cebada, la calle Santa Isabel y la de Embajadores, que aparecen en el listado en primero, segundo y cuarto lugar respectivamente. El resto de las calles donde se ubica algún Mercado figuran, todas ellas, con más de 50 comercios.

La variable "longitud de las calles" incide en favor de un mayor volumen de establecimientos cuanto más larga sea la calle. Por ello, nos parece más significativo establecer una jerarquía de calles comerciales en función de la densidad de comercios por kilómetro lineal.

El análisis se ha ceñido a las vías y plazas con un umbral mínimo de 25 comercios. Ha de tenerse en cuenta que muchas calles de reducida longitud pueden adquirir densidades muy elevadas, aunque no aparezcan en la relación. Se ha podido comprobar que estos casos se localizan entre vías de gran densidad comercial, formando un entramado que convierte a la zona en un área comercial.

Existen a nivel de vía/plaza densidades comerciales por kilómetro lineal muy contrastadas en el distrito, alcanzándose las máximas en las plazas de los Mostenses, con 970 comercios por kilómetro, y la Cebada con $884,6 \mathrm{com} . / \mathrm{Km}$. En general los valores más elevados se alcanzan en las plazas o calles cortas que cuentan con un mercado: así, el tercer y cuarto lugares, en cuanto a densidad, son ocupados por la calle Barceló y la plaza de San Miguel.

Asimismo, aparecen con valores elevados, aunque muy por debajo de los anteriores, calles muy comerciales, muchas de las cuales cuentan, además, con centros, galerías o pasajes comerciales. Así la calle Arenal con el Centro Comercial Decomisos y el Centro Comercial Arenal 8; la plaza de las Cortes, con la Galería del Prado; la Ribera de Curtidores, con las Galerías Piquer, Nuevas Galerías y una tercera galería comercial; 
la calle de la Montera, con dos pasajes comerciales, y la calle Carretas con otro pasaje comercial.

Hemos considerado como vías de elevada densidad las que alcanzan o superan los 150 comercios por $\mathrm{Km}$ lineal. Son 17 calles/plazas las incluidas en este umbral, aunque como se dijo anteriormente no han entrado en el análisis calles comerciales que cuentan con menos de 25 establecimientos y que podrían situarse por su densidad dentro de este grupo.

\section{CUADRO 5. DISTRITO CENTRO. CALLES Y PLAZAS CON MÁS DE 50 COMERCIOS ACTIVOS}

\begin{tabular}{lcc}
\hline CALLE O PLAZA & N. ${ }^{\circ}$ DE COMERCIOS & MERCADOS \\
\hline Plaza de la Cebada & 230 & $\mathrm{SI}$ \\
Santa Isabel & 199 & $\mathrm{SI}$ \\
Gran Vía & 150 & - \\
Embajadores & 143 & $\mathrm{SI}$ \\
Arenal & 135 & - \\
Ribera de Curtidores & 134 & - \\
Fuencarral & 125 & $\mathrm{SI}$ \\
Barceló & 123 & - \\
Toledo & 118 & - \\
Hortaleza & 110 & - \\
Mayor & 107 & $\mathrm{SI}$ \\
Atocha & 104 & $\mathrm{SI}$ \\
Augusto Figueroa & 100 & - \\
Plaza de los Mostenses & 97 & - \\
Montera & 76 & - \\
Preciados & 70 & $\mathrm{SI}$ \\
San Bernardo & 67 & - \\
San Miguel & 55 & - \\
Carretas & 51 & - \\
Barquillo & 50 & \\
Mesón de Paredes & 50 & \\
\hline
\end{tabular}

Fuente: Trabajo de campo. Elaboración propia.

Las vías/plazas de elevada densidad comercial son, por orden de mayor a menor: 
COMERCIOS POR KM

\begin{tabular}{|c|c|}
\hline 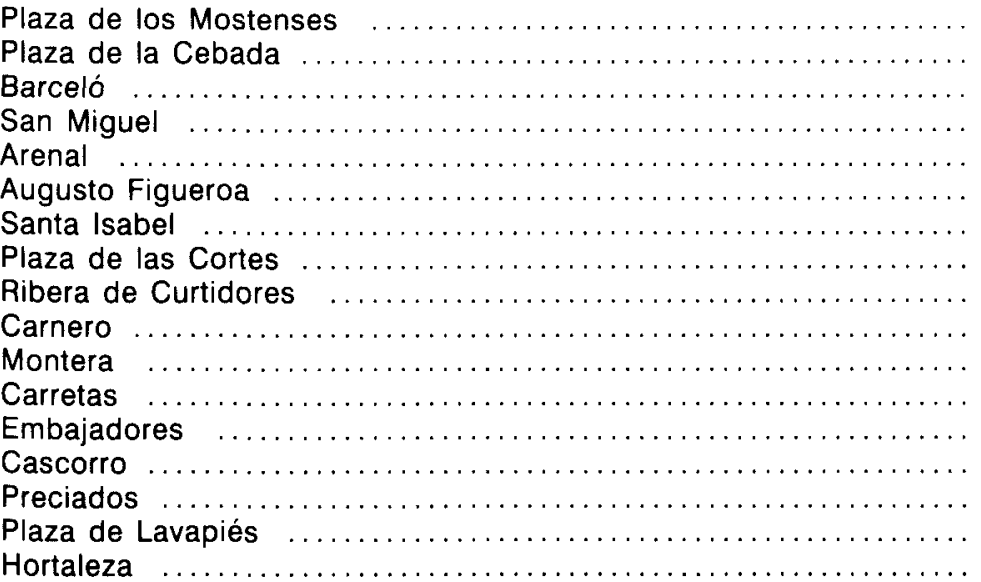 & $\begin{array}{l}970,0 \\
884,6 \\
585,7 \\
394,9 \\
346,1 \\
312,5 \\
284,3 \\
260,0 \\
257,7 \\
247,4 \\
237,5 \\
231,8 \\
213,4 \\
200,0 \\
170,7 \\
165,0 \\
152,8\end{array}$ \\
\hline
\end{tabular}

Los valores más elevados corresponden, como se dijo anteriormente, a los espacios donde existe una agrupación comercial en forma de mercado, galería o centro comercial. Figuran también en la relación, calles de gran tradición comercial como las de Preciados y Hortaleza. La primera de éstas no refleja su grado de intensidad comercial al incluir el tramo entre las plazas de Callao y Santo Domingo, de menor potencial comercial.

Por debajo de este umbral, entre 100 y 150 comercios por kilómetro lineal de calle se sitúan 16 , que por orden de mayor a menor son las siguientes:

COMERCIOS POR KM

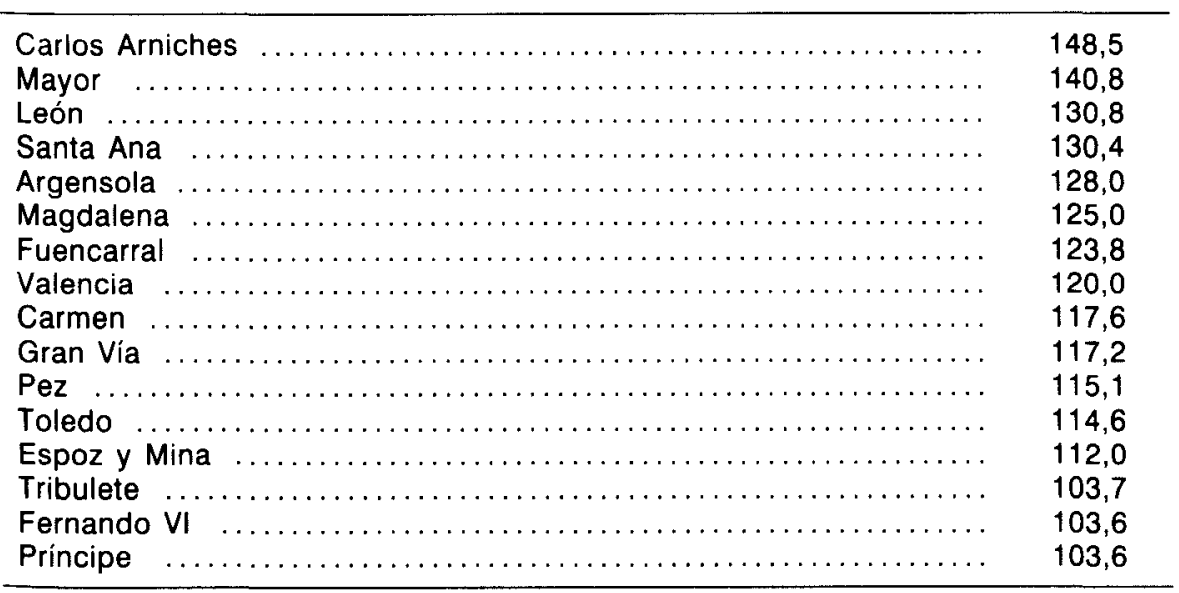


Por último, en el umbral inferior, entre 50 y 100 comercios por kilómetro lineal de calle se sitúan 16 vías o plazas:

COMERCIOS POR KM

\begin{tabular}{|c|c|}
\hline Corredera Baja de San Pablo. & 97,1 \\
\hline 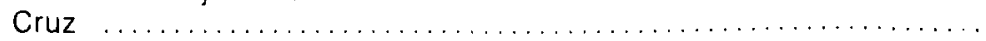 & 96,8 \\
\hline 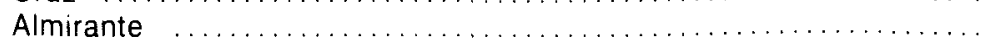 & 88,5 \\
\hline Puerta del Sol ........ & 86,7 \\
\hline Mejía Lequerica .................. & 84,8 \\
\hline Barquillo $\ldots \ldots \ldots \ldots \ldots \ldots \ldots$ & 84,7 \\
\hline$\ldots \ldots \ldots \ldots \ldots \ldots \ldots \ldots \ldots$ & 80,6 \\
\hline$\ldots \ldots \ldots \ldots \ldots \ldots \ldots \ldots$ & 79,5 \\
\hline$\ldots \ldots \ldots \ldots \ldots \ldots \ldots \ldots$ & 75,0 \\
\hline$\ldots \ldots \ldots \ldots \ldots \ldots \ldots \ldots$ & 67,7 \\
\hline$\ldots \ldots \ldots \ldots \ldots \ldots \ldots \ldots$ & 63,3 \\
\hline$\ldots \ldots \ldots \ldots \ldots \ldots \ldots \ldots \ldots$ & 61,8 \\
\hline$\ldots \ldots \ldots \ldots \ldots \ldots \ldots \ldots \ldots$ & 58,5 \\
\hline 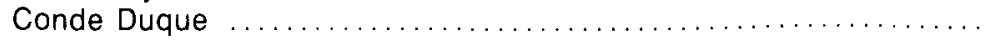 & 56,0 \\
\hline 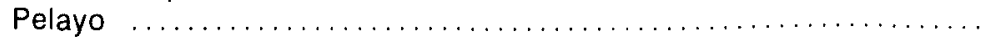 & 55,3 \\
\hline 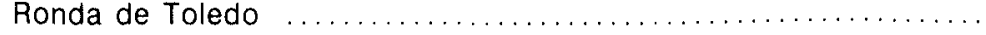 & 51,3 \\
\hline
\end{tabular}

No se toman en consideración las vías o plazas que tienen densidades inferiores a 50 comercios por kilómetro lineal.

Las 49 vías/plazas cuya densidad comercial supera este umbral, relacionadas anteriormente, quedan plasmadas en el plano correspondiente (Fig. 5). Su distribución espacial dibuja unas áreas comerciales destacadas:

- El área de Sol, con la Puerta del Sol y las calles de Arenal, Preciados, Carmen, Montera, Carretas, Mayor y Espoz y Mina. La calle Mayor destaca con una densidad media debido a que el tramo situado en el barrio de Palacio, más distante de la Puerta del Sol, es más institucional que comercial. En el entorno de Sol, se señala la plaza Mayor con las calles de Atocha y Toledo, muy comerciales en este tramo, aunque sus valores de densidad no sean de los más elevados, debido a su gran longitud y a que los extremos de ambas son menos comerciales. La calle de la Cruz destaca al este.

En esta zona de Sol, existe un buen número de vías y plazas, de escasa longitud, que cuentan con menos de 25 establecimientos pero alcanzan densidades muy elevadas. No han sido objeto de análisis en este trabajo y por ello no quedan reflejadas en el plano, sin embargo, forman un entramado comercial denso. No queremos dejar de citar, como los ejemplos más claros, las calles de Postas, Esparteros y Marqués Viudo de 


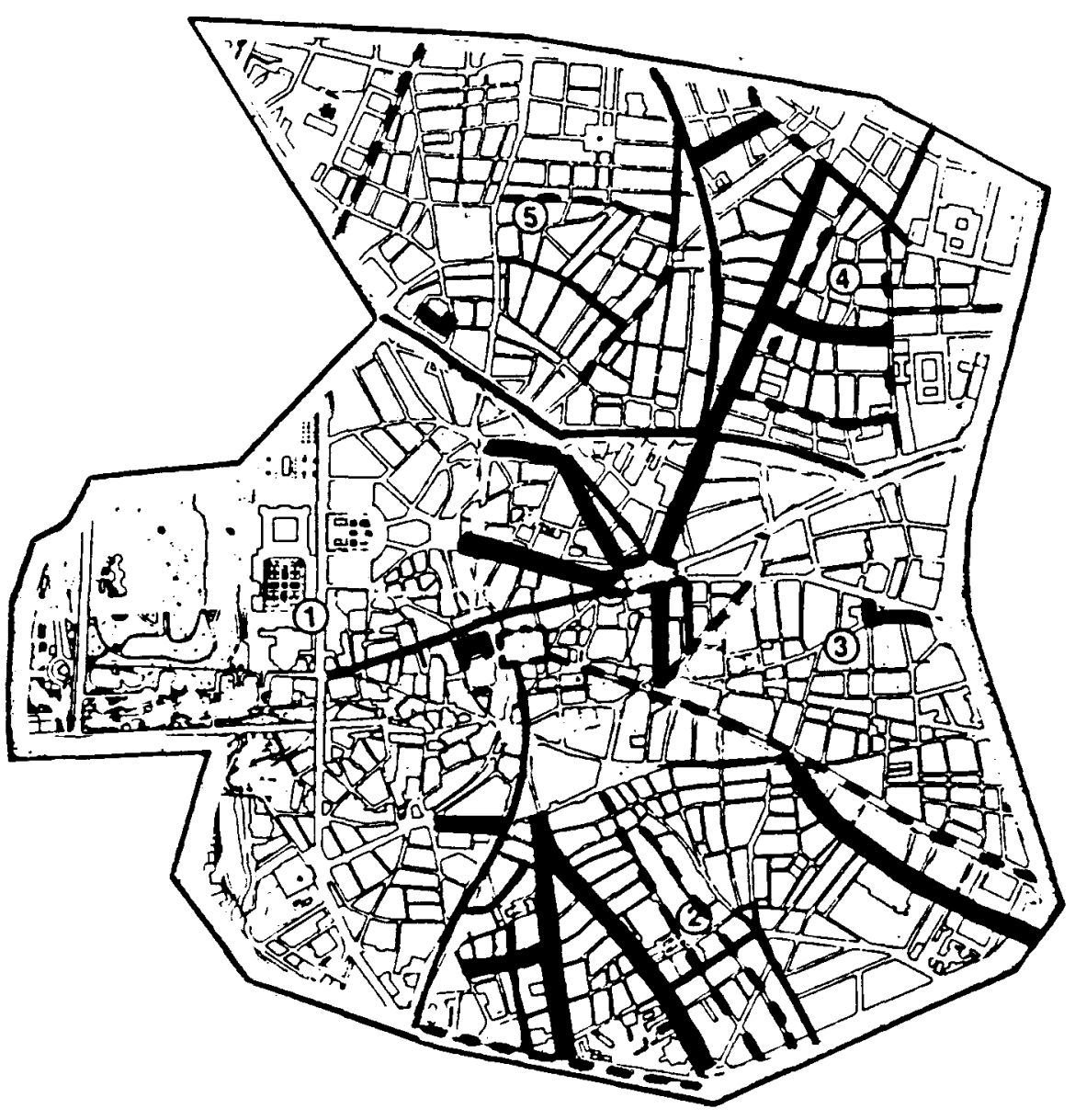

COMERCIOS / Km. LINEAL DE CALLE

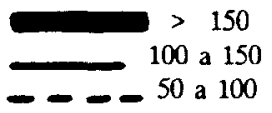

Fig. 5. Calles comerciales según densidad de comercios por kilómetro lineal. 
Pontejos, al suroeste; el primer tramo de la Carrera de San Jerónimo y la plaza de Canalejas, al oeste, y las del Maestro Victoria, Mesoneros y Tres Cruces, al norte.

- El triángulo comprendido entre las calles de Toledo, Embajadores y Ronda de Toledo, donde destacan la plaza de Cascorro, la Ribera de Curtidores, las calles de Embajadores y del Carnero y, secundariamente, Toledo, Santa Ana, Carlos Arniches y la Ronda de Toledo. Es el entramado fundamental del Rastro y entre estas vías existen otras más cortas que no aparecen en el plano por no haber sido objeto de análisis, pero que alcanzan elevadas densidades: la Ruda, Mira al Río Alta, Mira al Río Baja y la Plaza del General Vara del Rey.

La Ronda de Toledo destaca debido a la localización en ella del Mercado Puerta de Toledo.

En el costado oriental del Rastro quedan reflejadas en el plano las calles de Mesón de Paredes, el Amparo, Valencia y Tribulete y la plaza de Lavapiés. Se trata del área comercial de Lavapiés, de importancia secundaria. No queda reflejada en esta zona el área de comercio mayorista, de importante vitalidad, por no ser objeto de nuestro estudio este tipo de comercio.

- El barrio de Justicia destaca en el plano como un área comercial que gira en torno a los ejes de Hortaleza y Fuencarral y los Mercados de Barceló y Augusto Figueroa.

- Como áreas secundarias caben citarse la zona de las correderas Alta y Baja de San Pablo, en el barrio de Universidad y las calles de Atocha, Magdalena y Santa Isabel en Embajadores. De esta última área comercial es foco impulsor el Mercado de Antón Martín.

- Quedan reflejados en el plano puntos comerciales aislados que señalan localizaciones de Mercados o Centros Comerciales: las plazas de los Mostenses, San Miguel y la Cebada, con sus mercados y la Plaza de las Cortes con la Galería del Prado.

- Resulta, por último, interesante destacar la importancia como ejes comerciales de las vías de primer orden, que conectan el distrito con otras áreas funcionales de la ciudad: así, por ejemplo, la Gran Vía, las calles de Hortaleza y Fuencarral, o las de Atocha y Toledo.

\section{RASGOS CARACTERISTICOS DEL COMERCIO DEL CENTRO DE MADRID}

El centro como zona comercial es un espacio variado, donde conviven los comercios más antiguos de Madrid con formas comerciales de gran 
novedad, y se yuxtaponen áreas de importante vitalidad y potencia comercial, con otras de gran atonía. Zonas de comercio selecto contrastan con áreas de comercio popular. Calles de gran diversidad comercial se localizan junto a otras fuertemente especializadas.

En este capítulo se realiza una rápida visión de los aspectos más señalados de la actividad comercial del distrito, aquellos que le confieren su personalidad y carácter distintivo dentro del conjunto de Madrid.

\section{1. Áreas comerciales y calles especializadas}

La figura 6 refleja algunas de las formas comerciales más características del Centro en el momento actual:

a) Existen dos centros comerciales tradicionales: el primero se extiende entre el eje marcado por la calle Mayor-Puerta del Sol-Carrera de San Jerónimo y la Plaza de Callao-Gran Vía. Comprende dos grandes almacenes de las cadenas "El Corte Inglés» y "Galerías Preciados", un supermercado (dentro de El Corte Inglés), un Almacén Popular (SEPU) y multitud de comercios de tamaño pequeño y mediano, altamente especializados y en continua renovación. El núcleo principal de este centro son las calles peatonales de Preciados y Carmen. Es un centro comercial de carácter urbano y de influencia metropolitana, nacional e internacional.

El segundo centro es marginal dentro del distrito y tiene distinto carácter: se trata del centro comercial organizado en torno a la construcción de un gran almacén en los años setenta, El Cortes Inglés de Princesa, localizado en el extremo noroccidental del territorio. Este centro se desarrolla hacia el noroeste, por lo que su incidencia es pequeña en el distrito.

b) Zonas de predominio de comercio antiguo: hay pequeños sectores en todos los barrios de comercio tradicional de puerta de calle. Sin embargo, sólo se destaca en el plano el área más amplia con predominio de este tipo de comercio. Se halla a caballo entre los barrios de Palacio, Sol y Embajadores, coincidiendo con una zona del casco histórico de trama urbana poco renovada y callejero irregular.

La transformación que se está llevando a cabo en ella no tiende en principio a implantar nuevas formas comerciales o comercios de imagen moderna, sino a convertir los existentes en restaurantes o mesones.

c) Zona de Comercio Mayorista, en proceso de expansión en el entorno de la Plaza de Tirso de Molina y hacia el sur, dentro del barrio de Embajadores. Existe un contraste en ella, localizándose en el norte el 


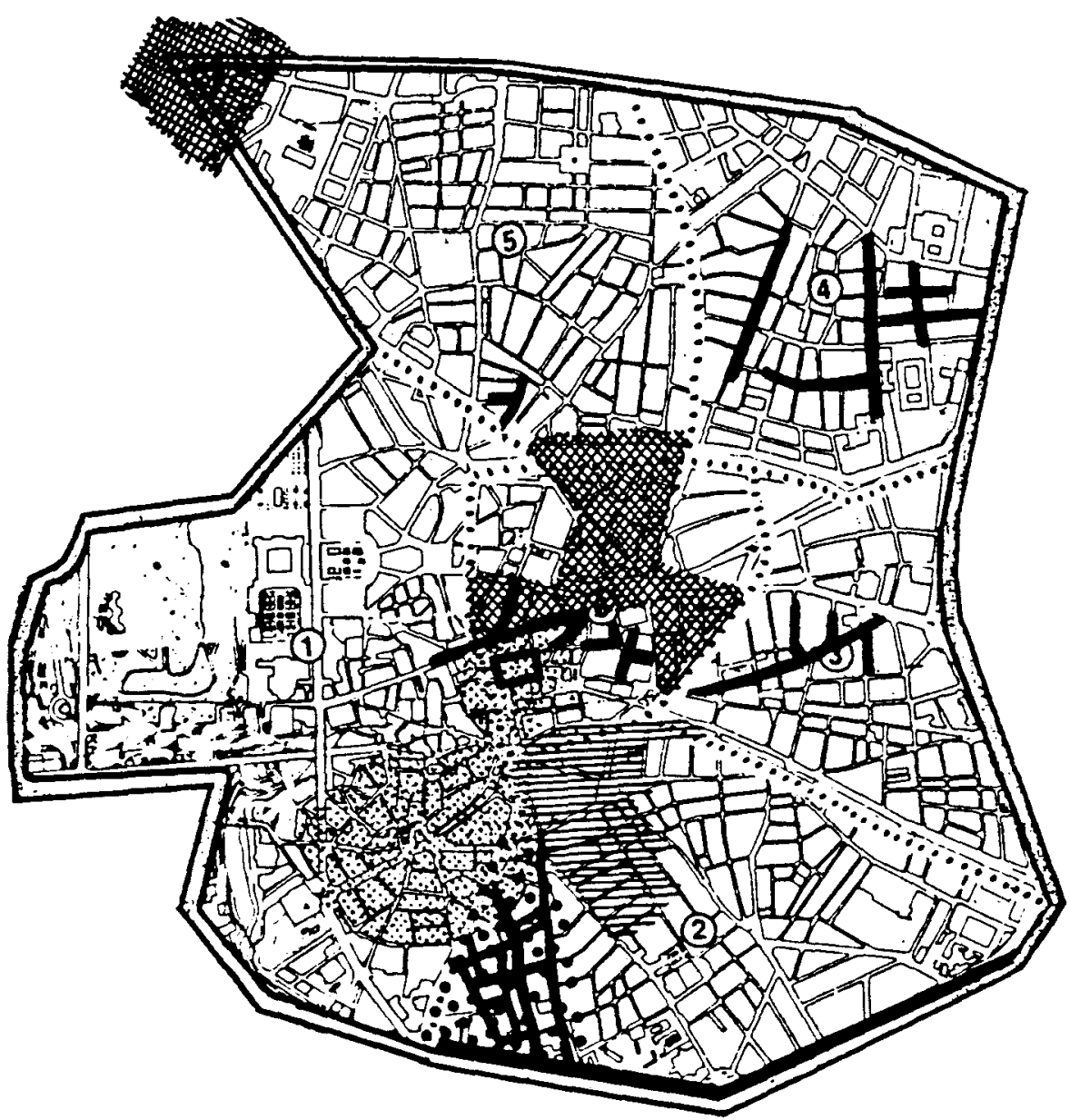

CENTRO COMERCIAL TRADICIONAL

ZONA DE COMERCIO MAYORISTA

ZONA DE COMERCIO ANTIGUO

$\because \because \because$ EL RASTRO

Calles especializadas

Fig. 6. Áreas comerciales y calles especializadas. 


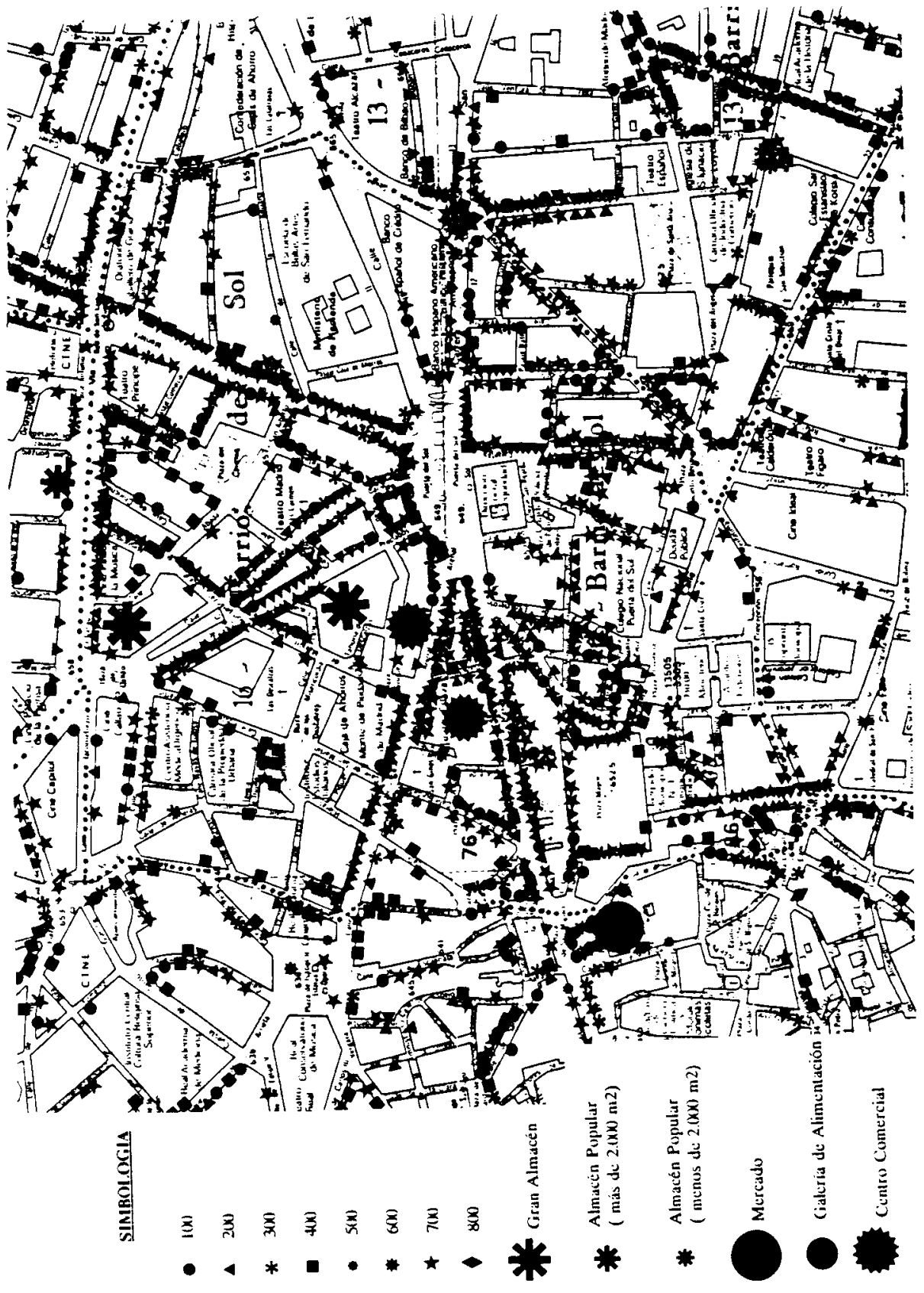

Fig. 7. Centro comercial tradicional de Sol. 
comercio de mayor calidad, y en el sur el de carácter popular y baja calidad, en relación con el comercio ambulante. En esta zona las calles de Juanelo, Espada, Esgrima y la del Amparo tienen una enorme vitalidad.

d) El Rastro es uno de los espacios comerciales más típicos del Centro de Madrid, semejante al "Mercado de las Pulgas» de París. Se caracteriza porque junto a los establecimientos e industrias existentes con carácter permanente, de los que ya se ha hablado, se montan los domingos y festivos "puestos", donde se expenden las más variadas mercancias, constituyendo el mercadillo más importante y de mayor tradición de la ciudad.

e) Calles especializadas. Destacamos en el plano las calles especializadas más importantes:

- En Antigüedades, La Ribera de Curtidores, Carlos Arniches, Mira el Río Alta, Mira el Río Baja, Carnero, Mellizo, Arganzuela, Bastero y la plaza General Vara del Rey (Rastro de Madrid), todas ellas en el barrio de Embajadores. Se trata de un sector especializado de gran tradición en Madrid. Incluye tres Galerias Comerciales de Anticuarios. Recientemente se ha enriquecido con la creación de un moderno Centro Comercial - Mercado Puerta de Toledo-, dedicado en gran parte a este sector.

En el barrio de Cortes este tipo de comercio es también tradicional en las calles del Prado, Santa Catalina, Ventura de la Vega y San Agustín.

- Filatelias y Numismáticas son especializaciones muy características y tradicionales en Madrid, con repercusión internacional. Se concentran principalmente en la plaza y calle Mayor, extendiéndose por las calles próximas. No podemos omitir el importante mercado ambulante de este sector que se monta todos los domingos en la Plaza Mayor, donde también se celebran ferias internacionales del sello.

- Imaginerías: especialización de antigua tradición. Destacan las calles Mayor, Bordadores, La Paz y sus alrededores, todas ellas dentro del barrio de Sol.

- Mercerías y fornituras: especializaciones clásicas que aún se mantienen en la plaza y calle Marqués Viudo de Pontejos, junto a la Puerta del Sol.

- Librerías: también es una especialización tradicional. Destacamos la calle de los Libreros, en el barrio de Universidad, donde, si bien han desaparecido algunos comercios antiguos, se han abierto otros nuevos. Se trata de libros nuevos y de segunda mano. Este tipo de librerías están 


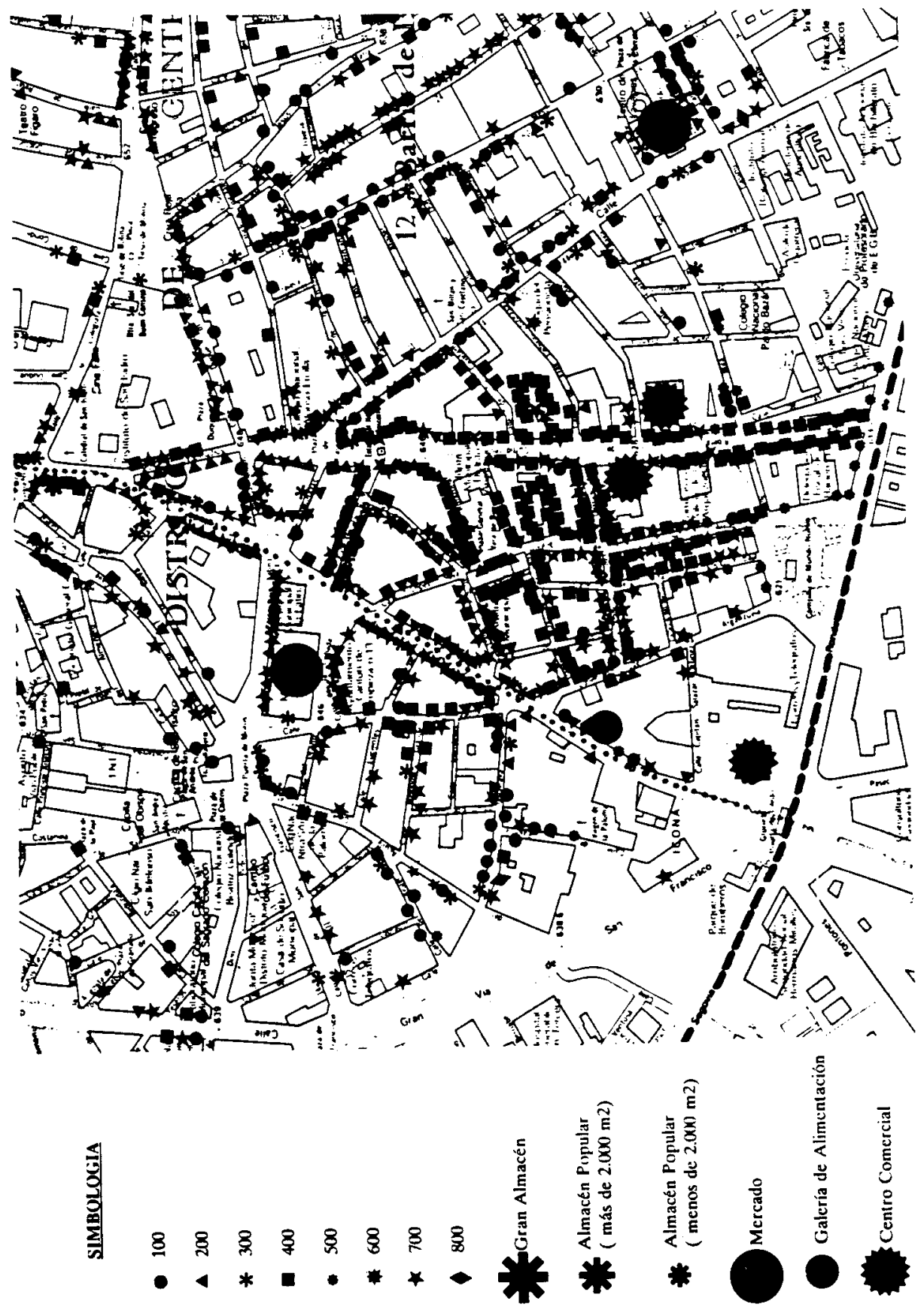

Fig. 8. Comercio minorista del Rastro de Madrid. 

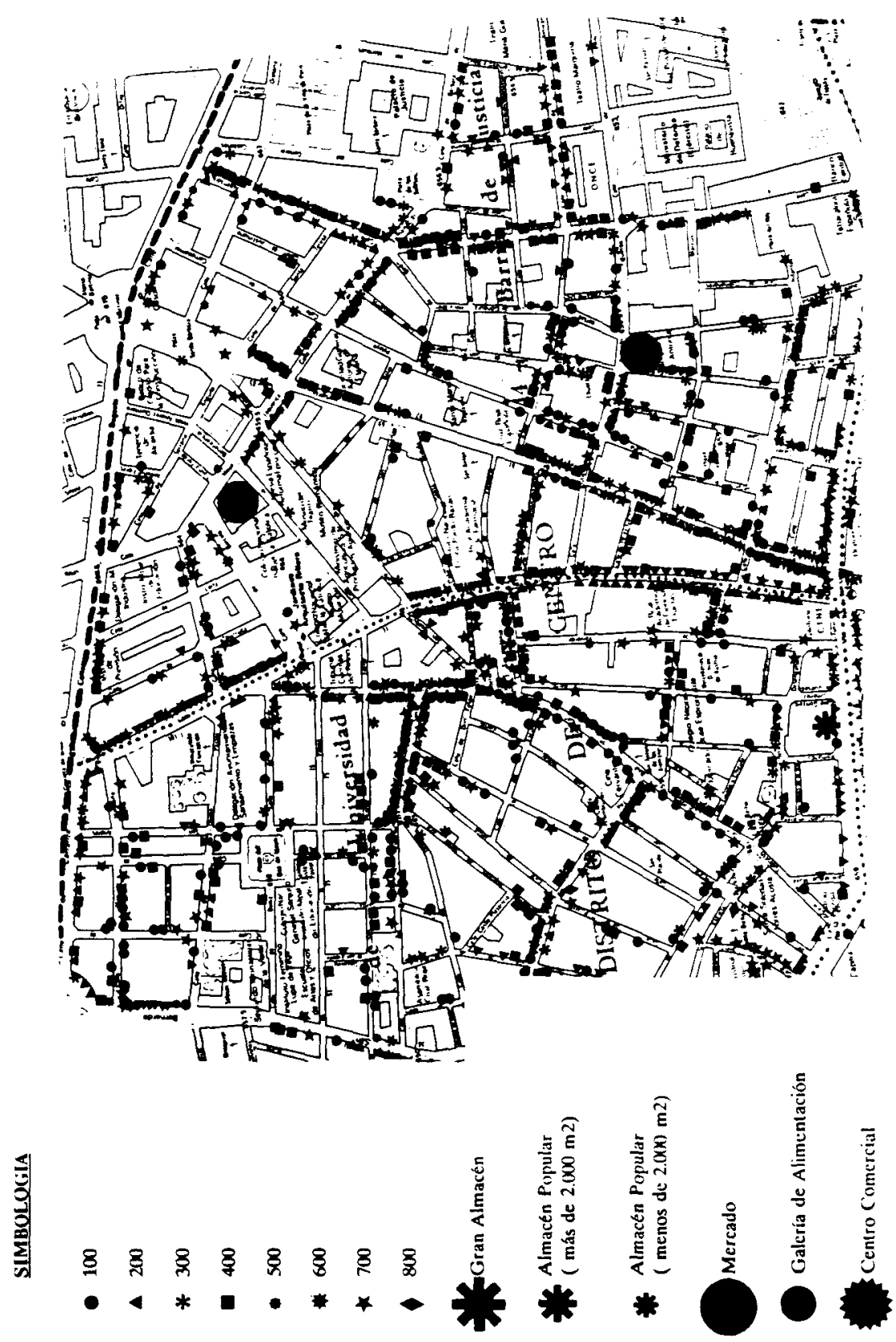

Fig. 9. Ejes comerciales de los barrios de Universidad y Justicia. 
bien representadas en el barrio de Cortes, aunque de forma más dispersa, sin concentrarse en ejes determinados.

Las librerías religiosas se localizan principalmente en el barrio de Sol, en las calles de La Paz, Marqués Viudo de Pontejos y Plaza de Benavente.

- Artículos de Bellas artes: son tradicionales los establecimientos de la calle de Hortaleza, donde recientemente se han abierto algunos nuevos. Es un tipo de comercio en expansión tanto en el distrito Centro como fuera de él.

- Vehículos automóviles y sus accesorios: se localizan preferentemente en las Rondas de Toledo, Valencia y Atocha, y en la Plaza del Campillo del Mundo Nuevo.

- Muestrarios de calzados: es una especialización nueva, de los últimos años. Predomina en la calle Augusto Figueroa y sus perpendiculares Barbieri y San Bartolomé.

- Diseño-moda: se puede considerar una especialización típica y muy característica de las calles Almirante, Conde de Xiquena, Piamonte y Marqués de Monasterio, en el barrio de Justicia, ligada a un área urbana de alta calidad.

- Bisuterías y complementos: dentro de la proliferación de este tipo de comercio en Madrid, destaca su alto grado de especialización en la calle del Amparo, donde si bien, la mayor parte de los comercios son de venta al por mayor, muchos atienden también al público en general. Se trata de una especialización muy reciente.

\subsection{Grandes superficies comerciales}

El distrito centro cuenta con los Grandes Almacenes y Almacenes Populares más antiguos de Madrid, aunque han experimentado fuertes transformaciones, incluso en su localización: Galerias Preciados en la calle del Carmen y El Corte Inglés en la de Preciados, actualmente; ambos abrieron sus puertas como Grandes Almacenes a comienzos de los años cuarenta, aunque su actividad comercial data de mediada la década anterior.

En la actualidad El Corte Inglés de Sol es el Gran Almacén de mayor superficie de Madrid con $33.888 \mathrm{~m}^{2}$ de venta y 1.919 empleados (CAM, 1991). Galerías Preciados de Callao es el tercer Gran Almacén en cuanto a superficie y el segundo en número de empleados, con $27.148 \mathrm{~m}^{2}$ y 1.765 empleados. (CAM, 1991). 


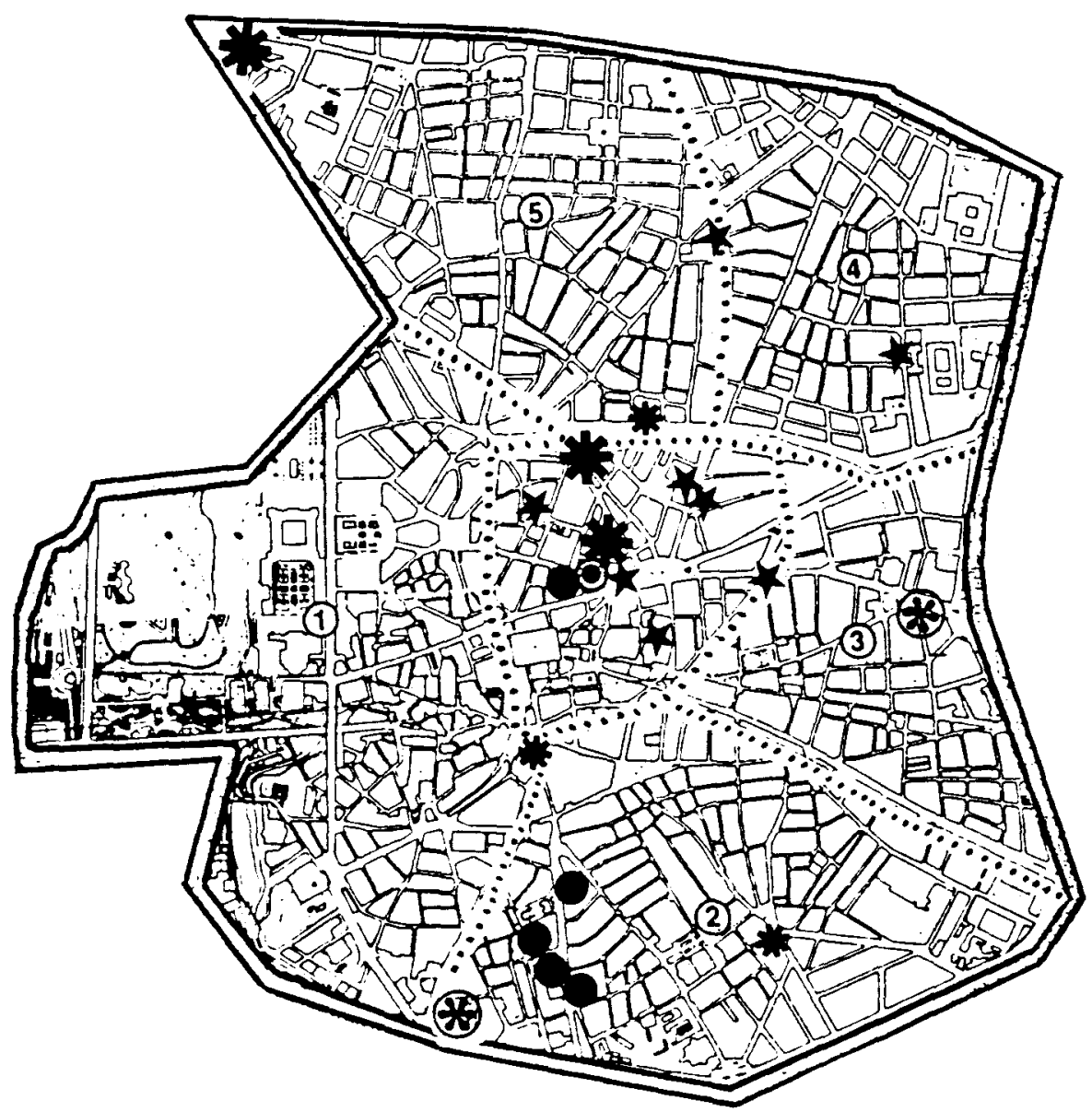

ThANDES ALMACENES

\#. ALMACENES POPULARES

4 pasajes y galerias comerciales

- CENTROS COMERCIALES ESPECIALIZADOS

O OTROS CENTROS COMERCIALES

* nuevos centros comerciales

Fig. 10. Grandes superficies y agrupaciones comerciales. 
El tercer Gran Almacén del distrito es El Corte Inglés de Princesa, creado con posterioridad, que tiene $31.041 \mathrm{~m}^{2}$ de superficie de venta y 1.294 empleados. (CAM, 1991).

SEPU (Sociedad Español de Precios Únicos) es el Almacén Popular más antiguo de Madrid. Se inauguró el 11 de agosto de 1934, en la Gran Vía, 32, donde continúa, ocupando parte del local del que fue el Gran Almacén al estilo francés más importante que tuvo Madrid - «Madrid París" - cuya vida fue muy corta.

Posteriores a éste son los dos Almacenes Populares de la cadena SIMAGO, situados en las calles Valencia y Toledo. Ambos cuentan con un departamento de alimentación, al estilo de los Almacenes Populares franceses.

Aunque los modernos centros comerciales suelen situarse en áreas periféricas por motivo de espacio y precio del suelo, recientemente se han abierto dos en el centro de Madrid: el Mercado Puerta de Toledo y la Galería del Prado, ambos integrados por comercios de lujo y dirigidos a una clientela elitista.

El Mercado Puerta de Toledo es un centro único en su género en España, aunque en la línea de Le Louvre des Antiquaires de París y la Place des Antiquaires de New York, con la novedad de la introducción de artículos modernos de diseño y firma de alta calidad. Se encuadra dentro de una tendencia reciente en España, pero ya común fuera de nuestro país, de la rehabilitación y cambio de uso de edificios antiguos localizados dentro de los cascos urbanos de las ciudades europeas y americanas, como medio de reactivar la vida urbana y evitar la degradación de los mismos. El establecimiento tiene $19.000 \mathrm{~m}^{2}$ construidos y más de 11.000 $\mathrm{m}^{2}$ de superficie comercial (CAM, 1991), concentrando a 63 anticuarios, 33 tiendas de diseño moda, 16 comercios de diseño de hábitat, 11 tiendas destinadas a joyería y orfebrería y dos Galerías de arte. Esta oferta se acompaña de sala de exposiciones, de espectáculos audiovisuales y de conferencias.

La Galería del Prado, abierta en 1989, continúa la línea de las Galerías comerciales de los grandes hoteles, aumentando la superficie y abriéndose al público en general. Tiene una superficie construida de $6.060 \mathrm{~m}^{2}$ y $2.972 \mathrm{~m}^{2}$ de venta (CAM, 1991). Consta de 39 locales, de los que 37 son comerciales. Los establecimientos integrados en ella son muy especializados y de alta calidad, reuniendo firmas de las más prestigiadas.

Aunque de características diferentes y de mayor antigüedad, destacamos como centro comercial de gran superficie la Galería Comercial Decomisos, centro tradicional de comercio preferentemente de artículos 
electrónicos y de fotografía. Ocupa un edificio antiguo con $5.722 \mathrm{~m}^{2}$ construidos y $4.288 \mathrm{~m}^{2}$ de venta. (M. ${ }^{\circ}$ de Economía y Hacienda, 1989). Concentra a 56 minoristas.

\subsection{Pasajes y Galeries comerciales}

Son típicos y tradicionales del centro de Madrid los pasajes y Galerías comerciales, situados habitualmente en la planta baja de edificios residenciales o de otros usos e integrados por un corto número de minoristas.

No constituyen grandes superficies porque no alcanzan $10 s 2.500 \mathrm{~m}^{2}$ de venta, umbral mínimo para que una concentración comercial se catalogue como tal.

El estado de conservación de esta forma comercial típica del centro de Madrid es muy desigual. Mientras algunas Galerías y Pasajes se remozan (Montera-Tres Cruces, Nuevas Galerías, Galerías Piquer...), otras se hallan en franco deterioro (Fuencarral-Corredera Alta de San Pablo), al tiempo que se crean nuevas (Barquillo 15). "Los Sótanos» de la Gran Vía, primera galería comercial importante de Madrid, ha sido cerrada para proceder a su reforma.

La mayoría de los Pasajes y Galerías se concentran en los barrios del Sol y Embajadores. En Sol las formas más características son los Pasajes y los Sótanos. Los pasajes comerciales suelen ser corredores de comunicación entre dos calles paralelas, abiertos en un edificio; los comercios se sitúan a ambos lados y suelen ser variados. Los sótanos comerciales también aglutinan diversidad de comercios. Tres quedan abiertos en el distrito: uno en la estación del Metro de Sol; un segundo en el aparcamiento de la Plaza de San Martín y el último en el paso subterráneo de la Plaza de Canalejas.

En el Rastro tienen gran tradición las Galerías Comerciales de anticuarios. Las más famosas son las "Galerías Piquer" y las "Nuevas Galerías", ambas remozadas recientemente. La actividad comercial de la zona ha permitido otro tipo de agrupaciones informales, como la de 15 chamarileros localizados en torno al patio de un antiguo edificio en la calle Carlos Arniches. El estado ruinoso del mismo ha provocado su cierre en los últimos meses.

\subsection{El comercio de Alimentación}

Mercados y establecimientos de puerta de calle son las formas tradicionales del comercio de Alimentación en el centro de Madrid. 


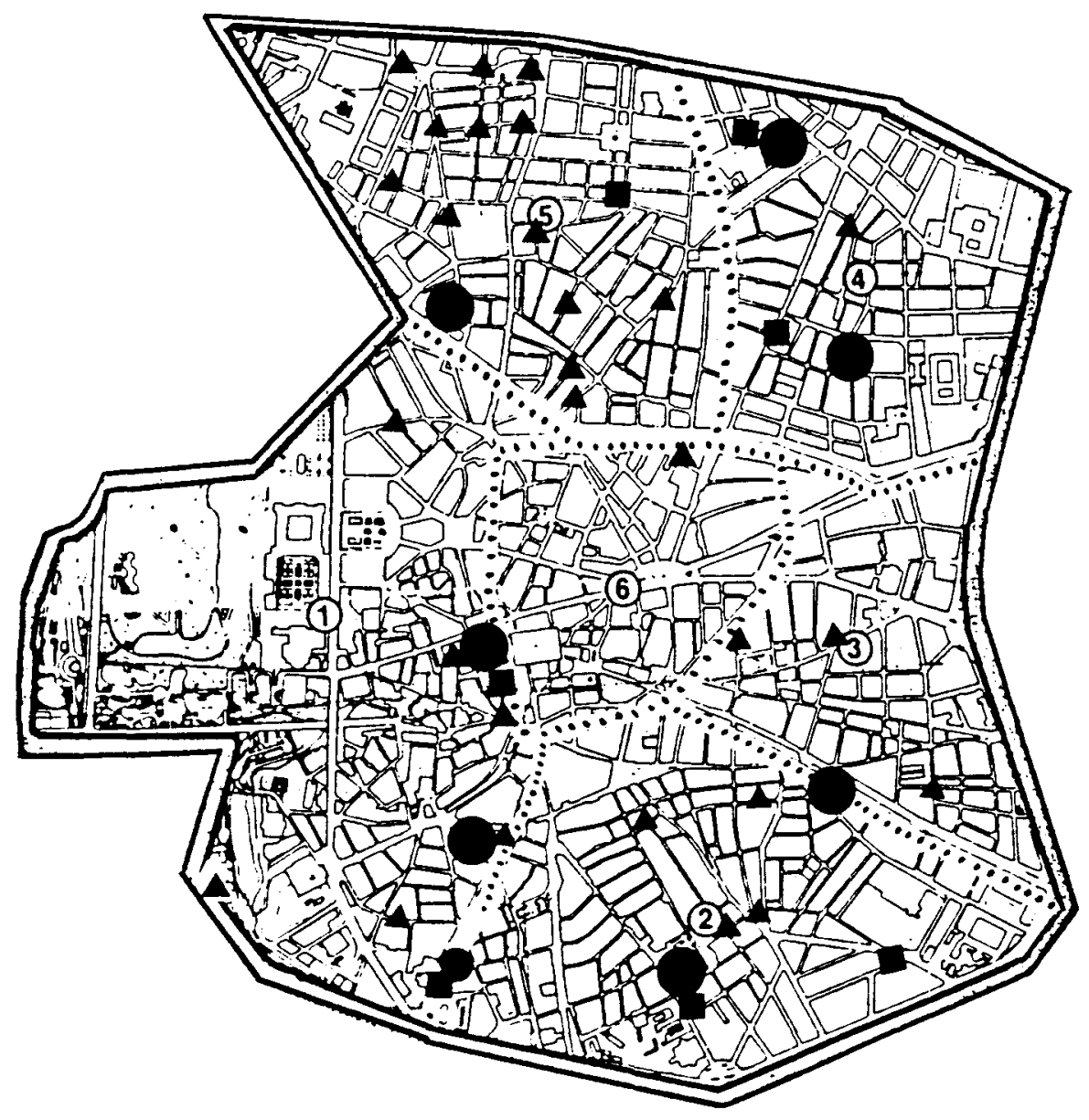

\section{MERCADO TRADICIONAL}

- galeria de alimentacion

- AUtOSERVICIO

- autoservicio CON CARACTER DE DISCOUNT

Fig. 11. Comercio tradicional y nuevas formas comerciales en el sector de Alimentación. 
El distrito Centro reúne siete Mercados de antigua creación. Su importancia como centros impulsores de actividad comercial es grande, dando origen con frecuencia a centros comerciales de barrio.

Una variante del Mercado, de creación madrileña y posterior en el tiempo, es la Galería de Alimentación, situada en los bajos de un edificio residencial. En este distrito no existe más que una, localizada en la calle de Toledo 109. Esta forma comercial prolifera en los barrios periféricos, dada la carencia de Mercados en ellos y por resultar más económica su construcción.

El comercio tradicional de puerta de calle están sufriendo una evolución muy clara y diversa:

- Los establecimientos especializados tradicionales (lecherías, panaderías, etc.) tienden a desespecializarse, transformándose en tiendas de alimentación en general, para cubrir mejor las necesidades inmediatas de la población residente, actuando de esta manera, como «tiendas de proximidad".

- Se crean nuevos comercios especializados: Herboristerías y alimentos dietéticos; jamonerías; comidas para llevar, entre las que proliferan las pizzerías; tiendas de Gourmet, etc.

- Se manifiesta una tendencia, por parte de las tiendas de alimentación en general, a transformarse en autoservicios, pasando muchas de ellas a formar parte de cadenas o sociedades de gestión, entre las que destacan UDACO, Grupo T y GAMA. El único cambio que tienen que hacer los establecimientos es incluir una caja registradora.

- Se crean autoservicios de nueva planta, todos ellos de reducido tamaño por la falta de espacio. En relación con otros distritos de Madrid, resalta la ausencia total en Centro de superservicios y supermercados.

- Como novedad, destaca la aparición de autoservicios con carácter de discount, cuya localización suele ser próxima a los Mercados. Este tipo de asociación comercial es tan claro que incluso en la Galería de Alimentación de la calle Toledo se integra un autoservicio descuento de la cadena DIA. Esta cadena es una de las de mayor vitalidad en el ramo.

En el plano se observa la distribución espacial de mercados y galerías de alimentación, como formas tradicionales, y autoservicios y establecimientos discount, como formas más modernas. Sol es el barrio con mayor carencia de unos y otros, justificada por su reducido volúmen de población. En contraposición, Universidad concentra 14 autoservicios, de los que uno es de discount, y un mercado. Esta abundancia está relacionada con el carácter residencial del barrio. 


\subsection{Comercio antiguo y nuevos tipos comerciales. Tendencias}

Como ya se ha señalado anteriormente, existe un buen número de establecimientos que están desapareciendo en el centro de Madrid: tonelerías, tiendas de tripas, boterías, cererías, cedacerías, cordelerías, esparterías..., en general el comercio de carácter artesanal, cuyos dueños son ancianos y no tienen descendientes que quieran continuar con el negocio. El cierre de este tipo de comercios se prevé a corto plazo.

Otros comercios en regresión son exponente de los cambios en los usos y costumbres. Tal es el caso de las tiendas de hábitos, las de fornituras y complementos militares, las sombrererías y las carbonerías.

Entre los comercios que han desaparecido se cuentan algunos tipos que nacieron hace unos años, tuvieron una rápida expansión y en definitiva su vida ha sido corta, sustituyéndose en algunos casos unos a otros. Así ha ocurrido con las tiendas de golosinas y las de libros baratos.

Como tipos en expansión destacan:

- Las tiendas de ordenadores, software y ofimática en general, en función del proceso de informatización del sector terciario y de la generalización del uso del ordenador.

- Las ópticas, debido en gran parte a un mayor control médico en las escuelas, al uso de los ordenadores y la televisión y al envejecimiento de la población.

- Las tiendas de confección, complementos y calzado, en relación con los rápidos cambios de la moda.

- Las de discos y sonido en general, posiblemente por el mayor poder adquisitivo de la población joven.

Surgen nuevos comercios, algunos de vida efímera, pero con un fuerte poder de expansión. Dos tipos concretos merecen destacarse:

- Los establecimientos abiertos 24 horas, entre los que figuran a la cabeza los pertenecientes a la franquicia 7 Eleven, que en un primer momento aparecieron asociados a las gasolineras, y en la actualidad se han extendido por áreas comerciales y zonas frecuentadas por la juventud. Se cuentan en el distrito siete establecimientos de este tipo. Dentro de este grupo se incluyen otros locales que, aunque no estén abiertos 24 horas, cubren un horario muy superior al habitual en el comercio: Ex-loco, City VIPS, VIPS, Wendy Fast Center...

- Los «Todo a 100 pesetas" son bazares donde se expende una gran variedad de artículos de menaje, mercería, perfumería y drogueria, com- 


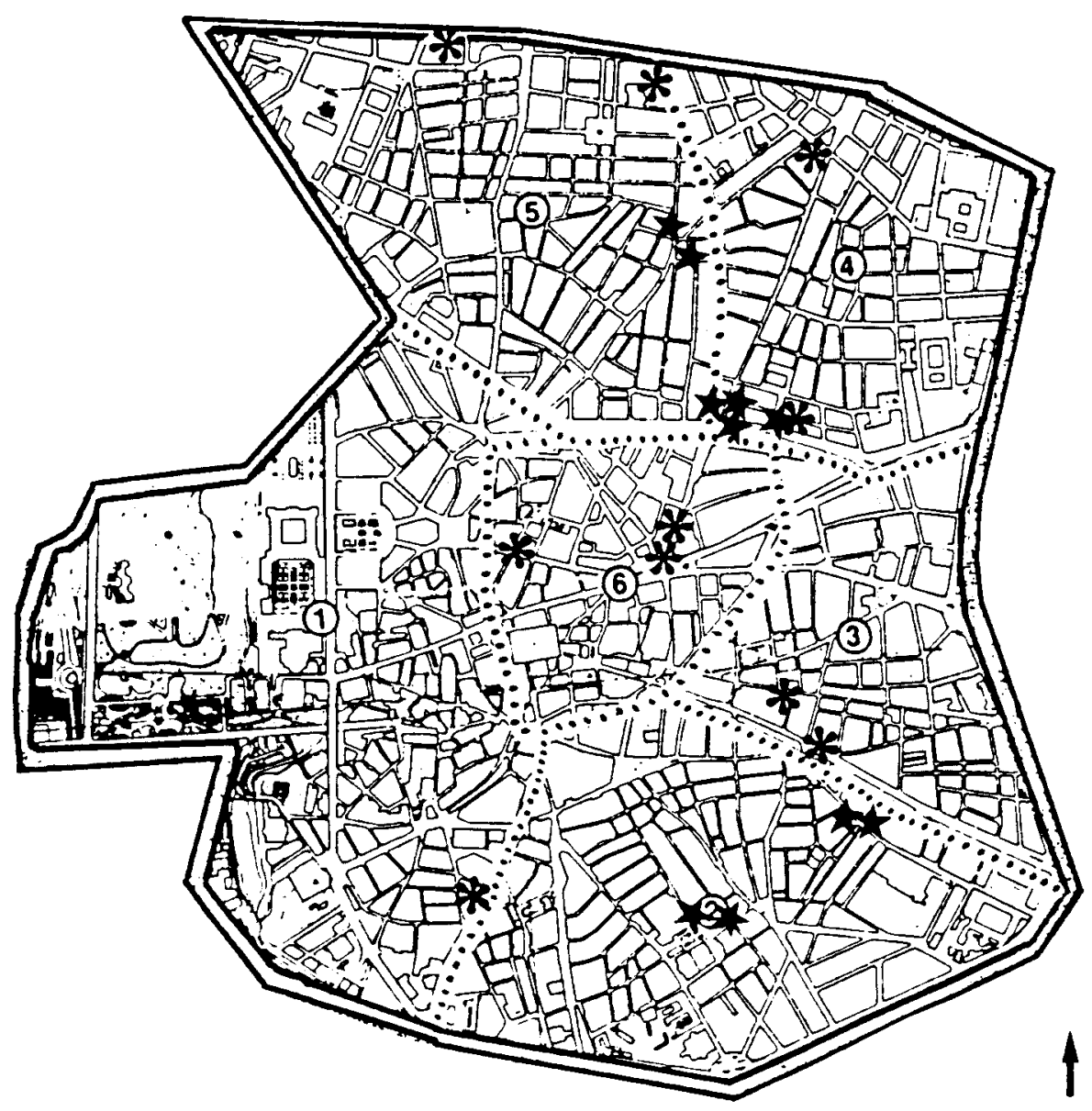

* abierto 24 horas

4 TODO A 100 PESETAS

Fig. 12. Nuevos tipos de establecimientos comerciales. 
plementos, bisutería, ferretería, papelería..., con precios únicos. Dentro de esta variedad, en algunos los precios son de 200,300, 500 y hasta 1.000 pts. Se localizan en áreas populares, a menudo en las proximidades de los mercados y están teniendo una gran aceptación; de ahí su rápido crecimiento.

En la figura se representan estos dos últimos tipos de comercio. Su distribución espacial difiere, localizándose los abiertos 24 horas, por lo general, en las vías más importantes: Alberto Aguilera, Atocha, Fuencarral, Gran Vía, San Bernardo, Puerta del Sol... En cuanto a las tiendas de aTodo a 100 pts." su localización no suele ser central. Cabe destacar una agrupación de cuatro de estos establecimientos en la calle de Hortaleza, próximos a la Gran Vía.

Por último, en esta rápida visión de la dinámica comercial del centro de Madrid, debe hacerse una referencia a la profunda transformación que se está llevando a cabo en los establecimientos de la Plaza Mayor, que en los últimos años pasan de especializaciones tradicionales de gran sabor y tipismo, a las clásicas tiendas de "souvenirs" para extranjeros, sin personalidad ni calidad.

\section{CONSIDERACIONES FINALES}

El presente estudio no agota en absoluto el interesante tema del comercio minorista del Centro de Madrid. Es un esquema fundamentado en datos que consideramos fiables y actualizados, por basarse en el trabajo de campo llevado a cabo personalmente y de forma rigurosa.

La elaboración de la información extraida de este modo, resulta una fuente valiosa para abordar nuevos análisis y profundizar en el conocimiento del comercio del Centro de la ciudad.

Las transformaciones que, cada vez a mayor ritmo, se están operando en el centro de Madrid - como en el de tantas otras ciudades españolas y occidentales - merecen una observación y un análisis continuo y minucioso. La actualización de los datos y la confrontación de los mismos en períodos de tiempo cortos son de vital importancia, en este sentido.

Valga como ejemplo de lo dicho nuestra experiencia personal del último año trabajando en el área: desde la fecha de referencia de los datos que se presentan (Enero-febrero de 1992) hasta el momento en que se escriben estas líneas (primavera de 1993), han cerrado un buen número de establecimientos antiguos, han abierto varios de los catalogados como nuevos tipos y muchos negocios han cambiado de actividad. 
Queremos incidir sobre la rapidez con que en los últimos años están desapareciendo tipos de comercios tradicionales, cuya protección sería deseable, al menos como legado cultural a futuras generaciones.

Los procesos de cambio en tipos y localizaciones dentro del casco histórico madrileño son poco conocidos y también son dignos de un estudio pormenorizado.

Por último, merece atención especial el comercio ambulante, en forma de mercadillos o de puestos aislados en la calle o en las estaciones de metro. La mayoría de los vendedores son gitanos o inmigrantes extranjeros. Su proliferación está estrechamente ligada a la expansión reciente del comercio mayorista de tipo más popular, así como a la del comercio artesanal.

Todos estos temas, y otros más de interés singular, hacen del Centro un espacio de análisis privilegiado.

\section{FUENTES Y BIBLIOGRAFIA}

Ayuntamiento de Madrid (1988): Madrid. Anuario Estadístico, 796 págs.

- (1990): Mercados. Enero 1990. JG/ML., 6 págs.

- (1988): Relación de Galerías de Alimentación al 12-VII-1988. jma/mjo, 7 págs.

A.A.V.V. (1986): "Viejo y nuevo comercion, Monográfico de Alfoz, N. 27.

- (1991): “Áreas comerciales", Monográfico de Urbanismo, N. ${ }^{\circ} 14$.

C.A.M. (1993): Censos de población y viviendas de 1991 de la C.A.M. I Características demográficas básicas y fecundidad de la población. Consejería de Economia.

- (1992): Listados del Comercio Minorista de los barrios del distrito Centro.

- (1992): Listados del Comercio Minorista de los barrios del distrito de Arganzuela.

- (1992): Listados del Comercio Minorista de los barrios del distrito de Retiro.

- (1992): Listados del Comercio Minorista de los barrios del distrito de Salamanca.

- (1992): Listados del Comercio Minorista de los barrios del distrito de Chamartín.

- (1992): Listados del Comercio Minorista de los barrios del distrito de Tetuán.

- (1992): Listados del Comercio Minorista de los barrios del distrito Chamberi.

- (1986): Censo de establecimientos comerciales minoristas de la Comunidad de Madrid. Datos estadísticos del Censo. Dirección General de Comercio y Consumo. Madrid 199 págs.

- (1986): Censo de establecimientos comerciales minoristas de la Comunidad de Madrid. Guia de establecimientos comerciales. Madrid. Dirección General de Comercio y Consumo. 309 págs.

- (1991): Guia de grandes superficies comerciales de la Comunidad de Madrid. Madrid. Consejería de Economía. 88 págs

CAMPos Romero, M.L. (1974): “Estudio geográfico del Rastro madrileño», en Geographica, Núms. 1-4 enero-diciembre 1974. Instituto de Geografía Aplicada. C.S.I.C. págs. 133-212

Carrera Sánchez, M.C. (1989): “La actividad comercial en la Comunidad de Madrid», en V.V.A.A. Madrid, presente y futuro. Madrid, Akal.

C.O.C.I.M. (1973): Localización, estructura y dinámica del comercio de Madrid. Madrid.

CHECA SÁNCHEZ A. (1975): Estructura comercial de Madrid: Estudio geográfico de Grandes Almacenes. Madrid (Tesis Doctoral inédita).

- (1976): "Estructura y localización del comercio minorista de Madrid", Boletín de la Real Sociedad Geográfica, Tomo CXII, Parte I. 
- (1980): «El comercio de Madrid en el año 1830». Aportación española al XXIV Congreso Geográfico Internacional. Japón, agosto-sept. 1980; Madrid, págs. 51-58.

- (1988): "Localisation et organisation spatiale du commerce de detail de Madrid", en MERENNE. SCHOUMAKER, B. (Ed.), Le commerce de detail face aux mutations actuelles. Les faits et leur analyse. Actes du Colloque International. Liege 1987, págs. 231-240.

- (1990): "Les changements du commerce du Centre de Madrid", en «Le commerce des centres villes". Actes du Colloque de Limoges, págs. 344-359.

CHeCA SÁNCHEZ, A. y LORA-TAMAYO D OCON, G. (1992): "Comercio tradicional y nuevas formas de comercio en el centro de Madrid" en Barata Salguelao, T. (Ed.), Commerce et urbanisme commercial. Universidade de Lisboa, págs. 297-316.

Checa Sanchez, A. (Dir) (1990): Primeras Jornadas de Geografía y Comercio: Grandes superficies comerciales. Madrid, 460 págs.

Dominguez Almaraz, L. (1991): "El Mercado Puerta de Toledo", en "Primeras Jornadas de Geografia y Comercio: Grandes Superficies Comerciales», págs. 251-264. Madrid.

EPYPSA (1986): El comercio en la C.A.M. Madrid, C.A.M.

FERNÁNDEZ, A. (1989): “Propuesta de revitalización del centro comercial Carmen/Preciados", en Curso de Urbanismo de Áreas Comerciales. Madrid, C.O.A.M., págs. 179-188

Gamir Orueta, A. (1993): Las actividades económicas en las áreas afectadas por los PERI del casco antiguo. Informe inédito.

LORA-TAMAYO D'OCON, G. (1990): El comercio minorista en el municipio de Madrid", en El barrio de la Concepción de Madrid: estudio de un área residencial. Tom. II, págs. 765-794. Colección Tesis Doctorales. Madrid, U.C.M.

Lora-Tamayo D ocon, G. y Bodega Fernández, I. (1991): “Primera nota sobre Grandes Superficies comerciales en la Ciudad de Madrid", en Primeras Jornadas de Geografia y Comercio: Grandes Superficies Comerciales, págs. 164-189. Madrid.

Lora-Tamayo D'ocon, G. et alii (1992): "Nuevas formas comerciales de gran superficie en la Comunidad de Madrid", en Espacio, Tiempo y Forma. Madrid, U.N.E.D., Serie VI, 5, págs. 107-134.

M. DE Economia y Hacienda (1989): Centros comerciales. Mercados minoristas. Dirección General de Comercio Interior. Colección Estudios, 41, 2 Volúmenes.

Ríos CLEMENTE, M.A. et alii (1991): “Los nuevos centros comerciales como respuesta a un nuevo estilo de vida. Su plasmación en la comunidad madrileña», en Primeras Jornadas de Geografía y Comercio: Grandes Superficies Comerciales, págs. 216-234. Madrid.

Rodriguez Tarduchy, M.J. (1974) : "El centro Carmen/Preciados Je Madrid a la luz de la problemática general de las áreas peatonales", en Ciudad y Territorio, N. ${ }^{\circ}$ 2, págs. 29-36.

Servicio Sindical de Estadística (1969): Comercio al por menor.

VENKO-MARK (1975): Atlas comercial de detallistas de Madrid.

VILLARIN, J. (1986): «El Rastro: refugio del desarraigo", Alfoz n. ${ }^{\circ} 33$, págs. 44-47. 


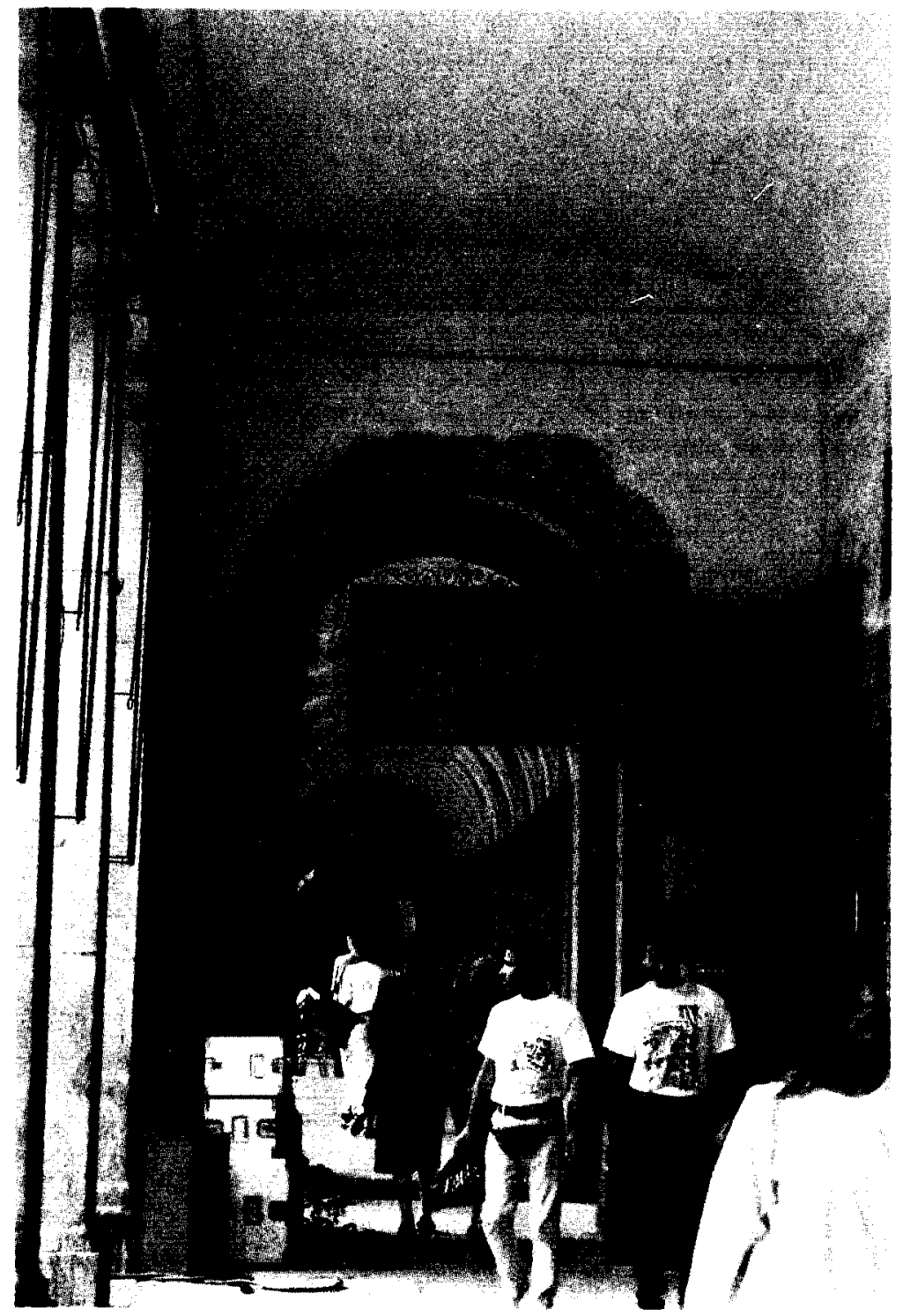

Foto 1. Plaza Mayor: bajo los soportales y en su entorno subsisten las Filatelias y Numismáticas. 

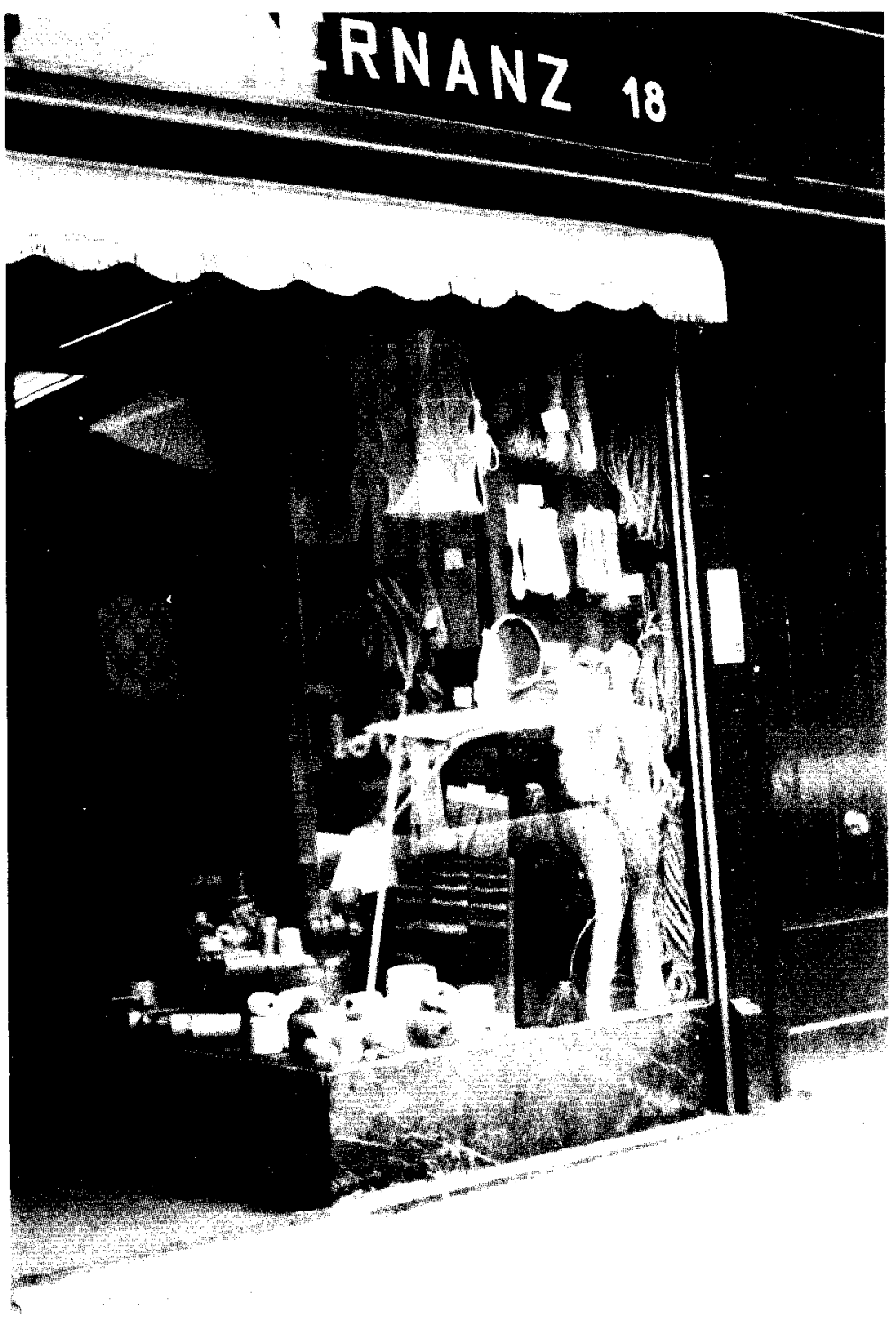

Foto 2. "Casa Hernanz", espartería y cordeleria, en la calle Toledo. 


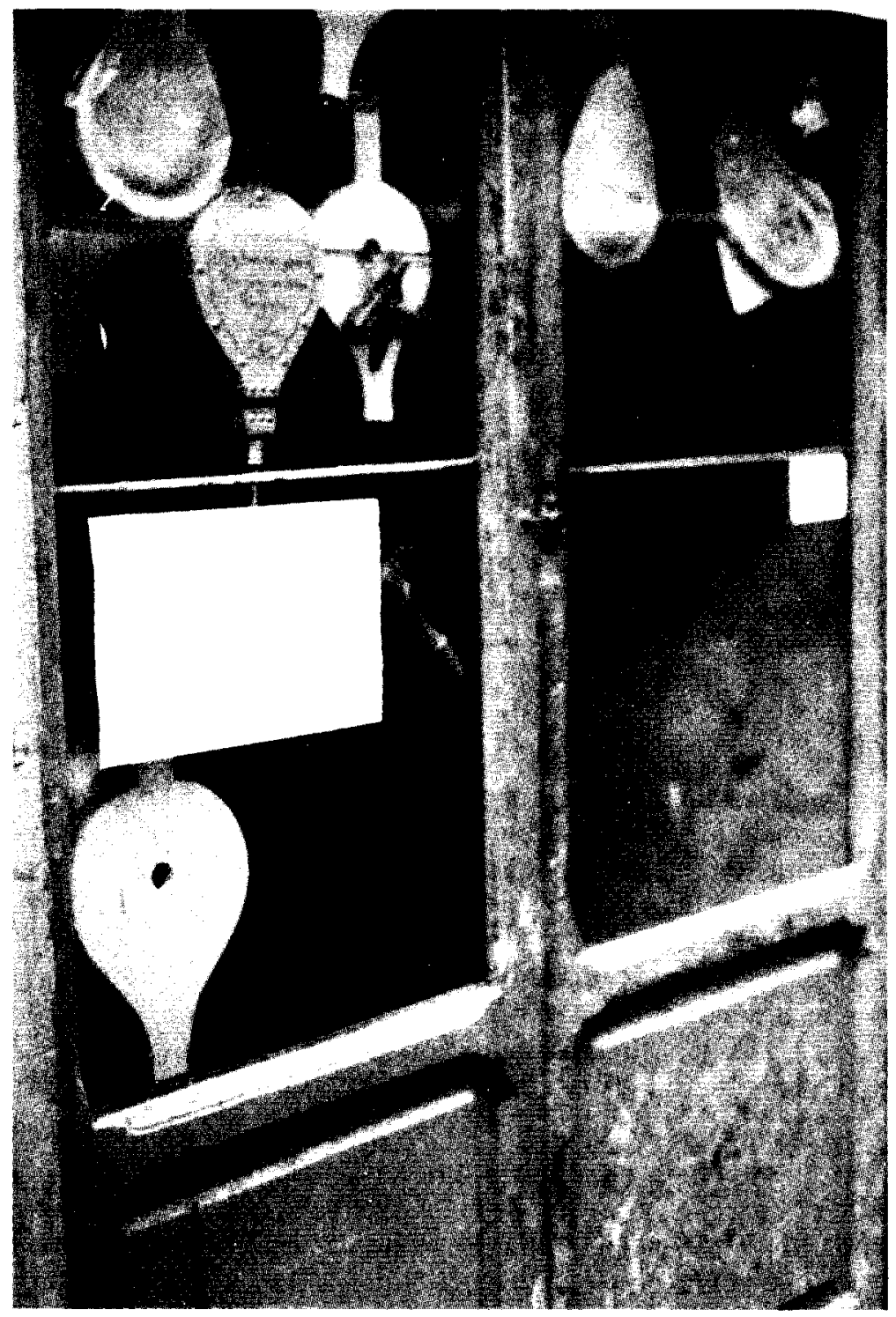

Foto 3. Tienda de botas y fuelles en la Cava Baja. 


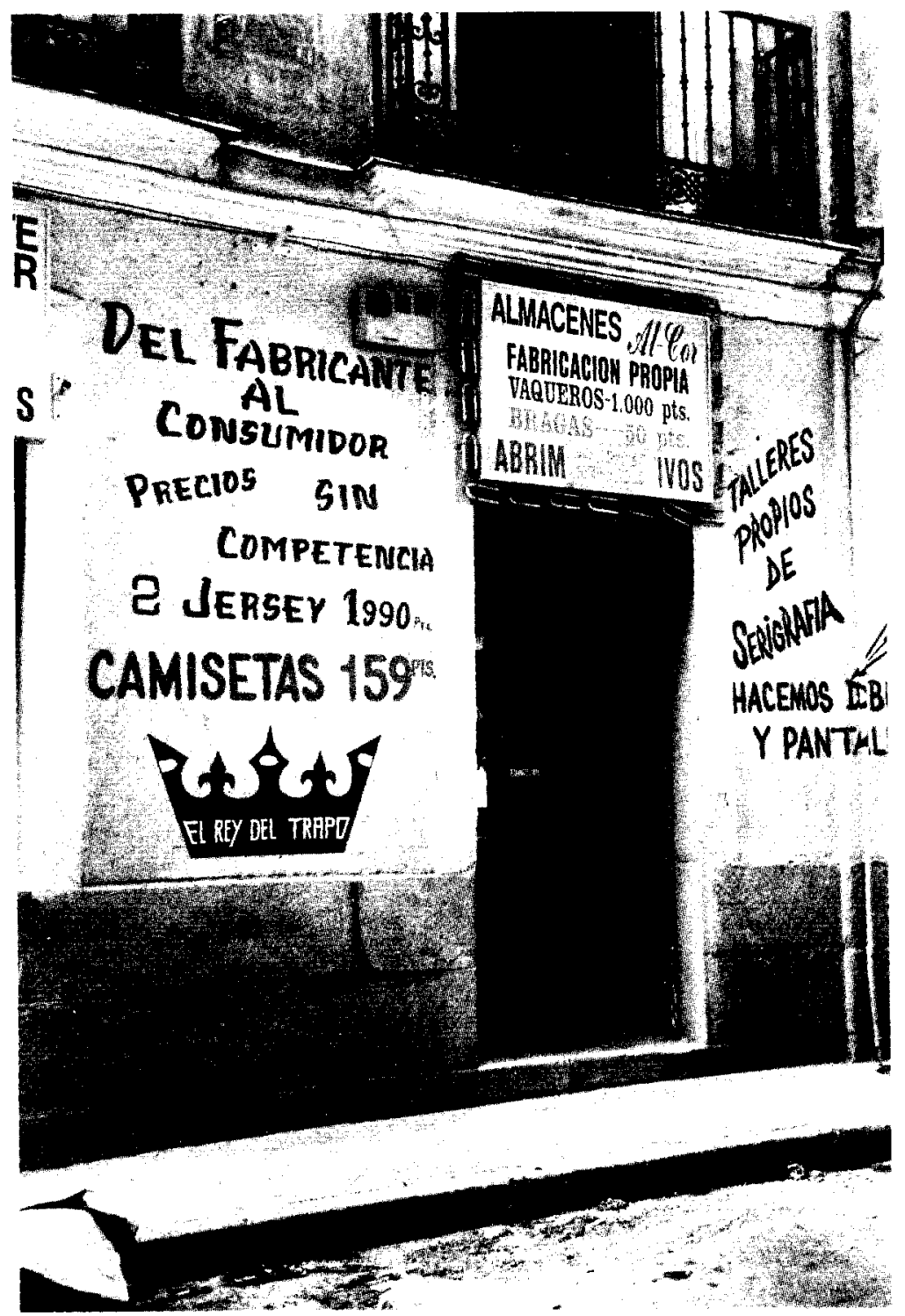

Foto 4. En el barrio de Lavapies proliferan los comercios mayoristas y minoristas de confección de baja calidad. 


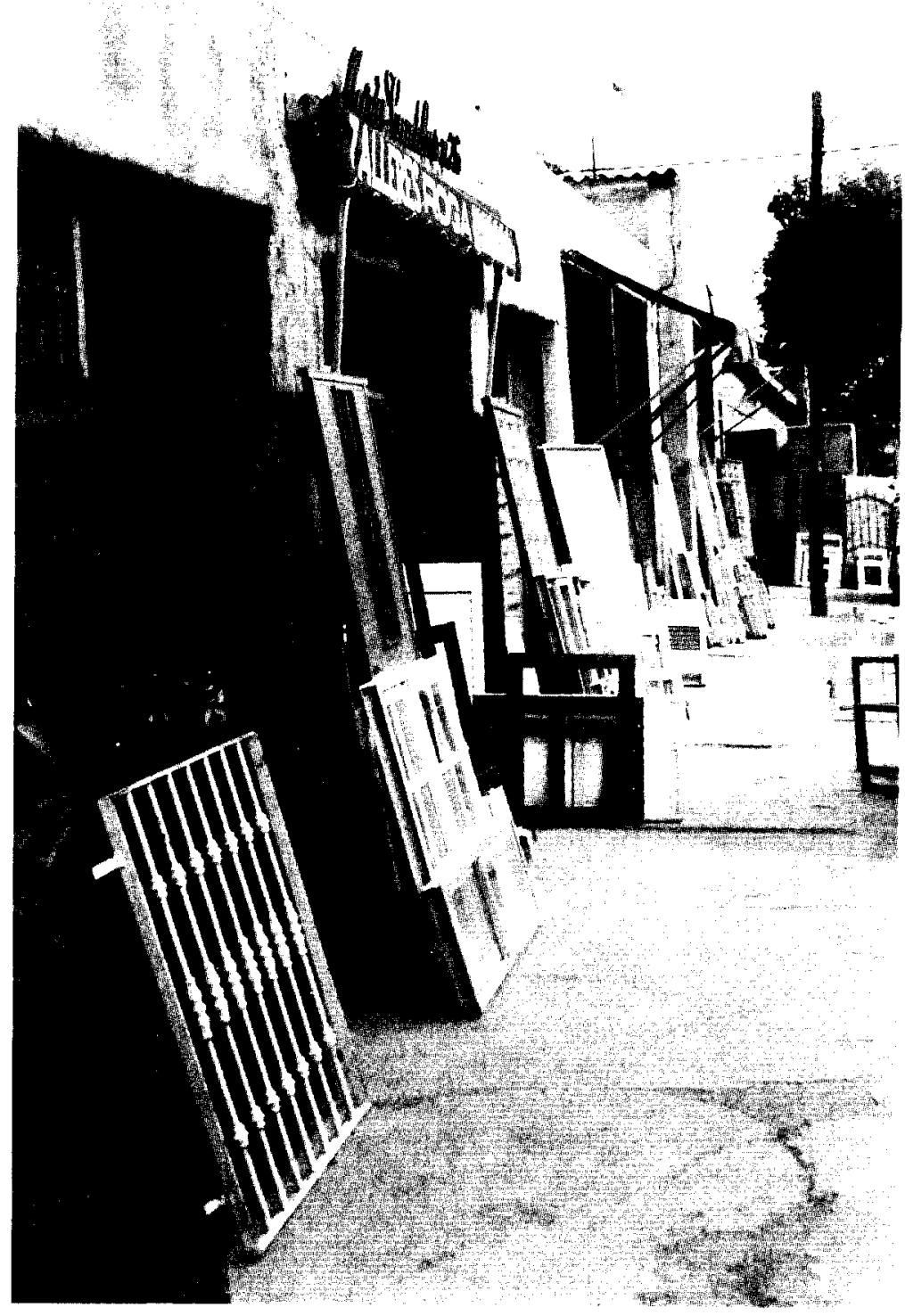

Foto 5. La Ribera de Curtidores, cerca de las Rondas se especializa en cerrajeria, trabajos de forja y piedra artificial. 


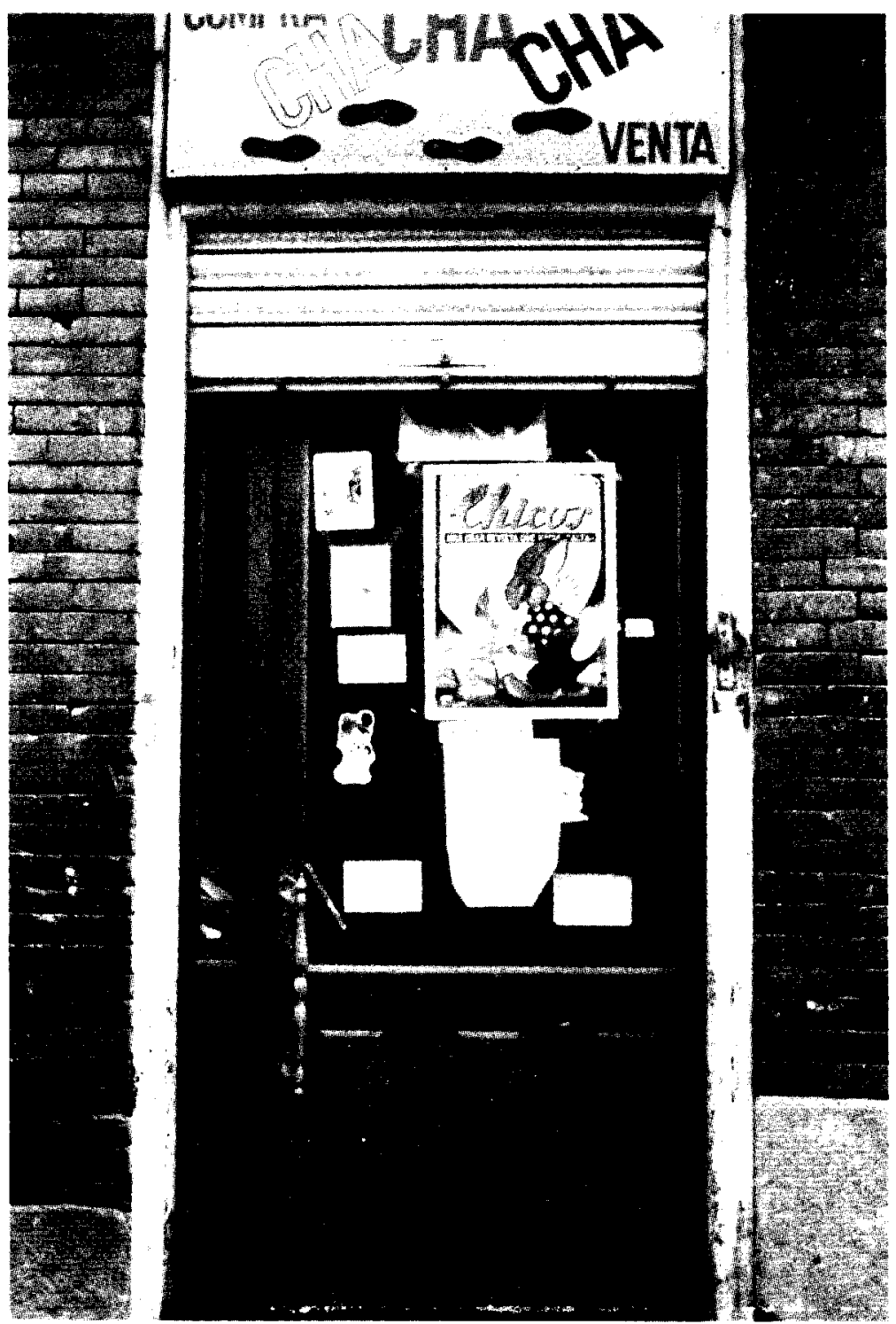

Foto 6. Son típicas las tiendas de compra-venta de toda clase de articulos en el Rastro. 


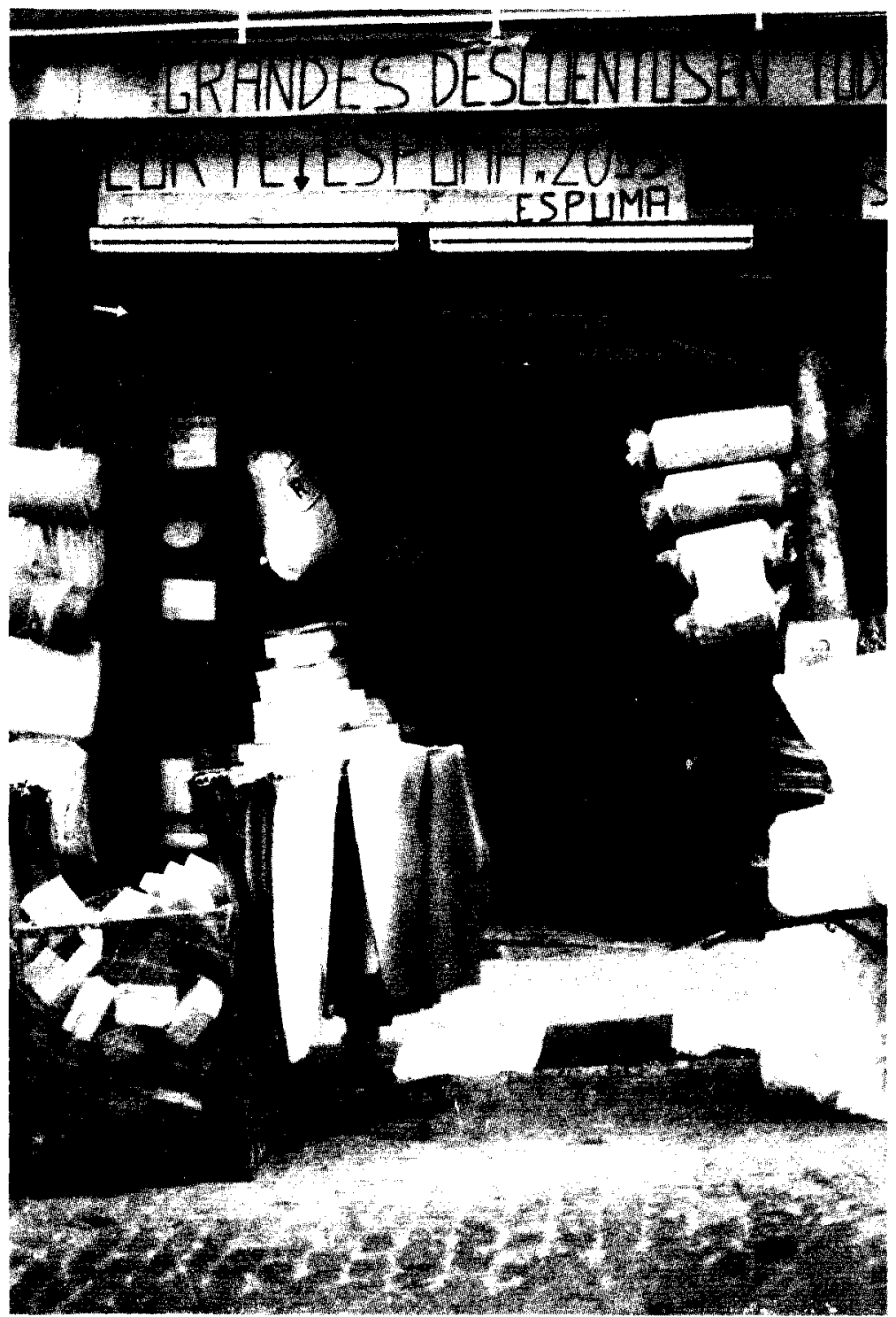

Foto 7. Establecimiento especializado en la venta de gomaespuma, en la calle Carlos Arniches. 


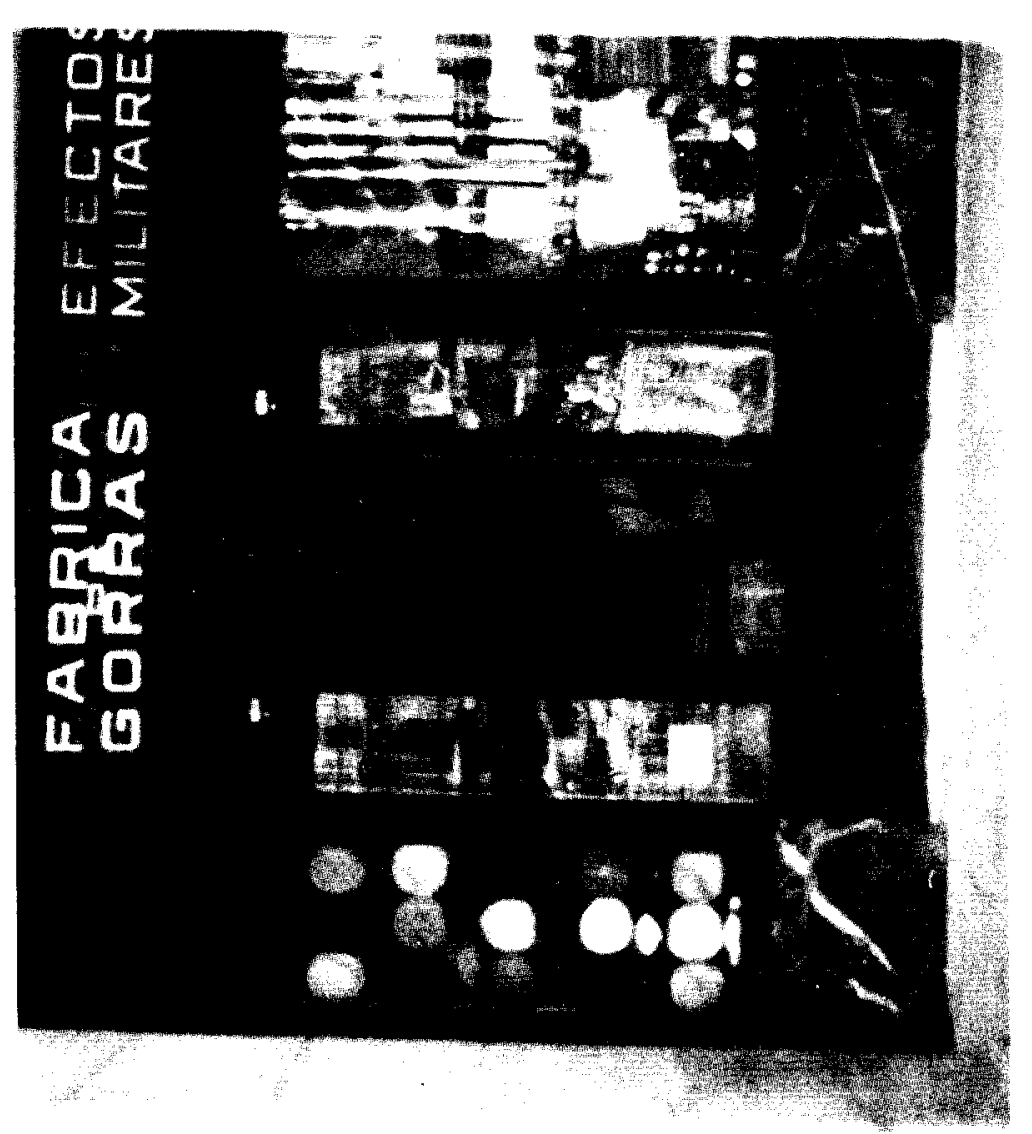

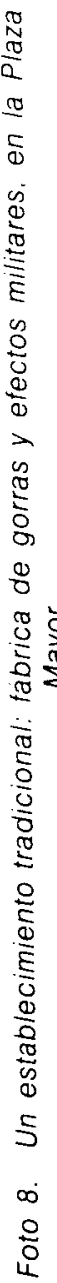




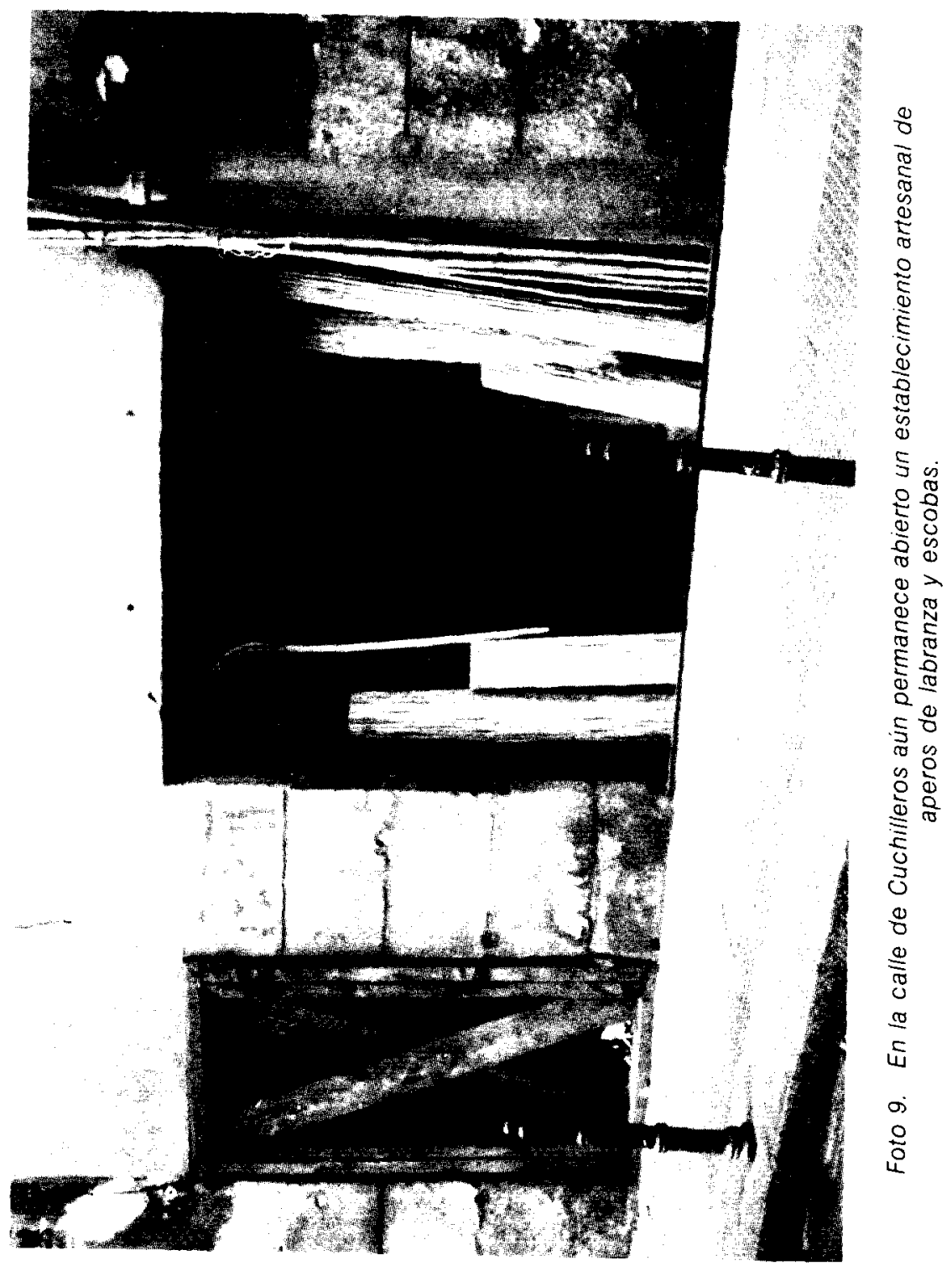




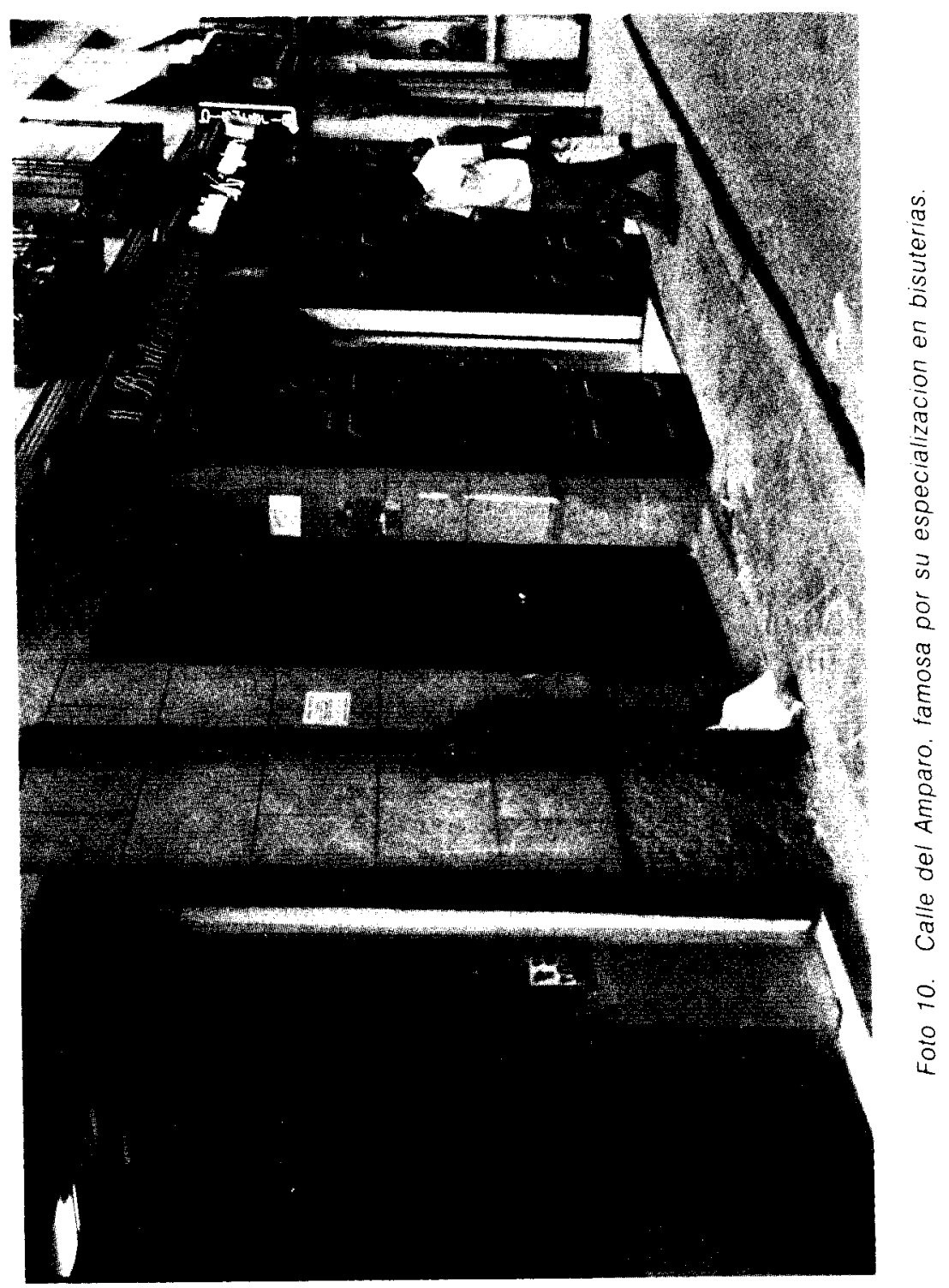




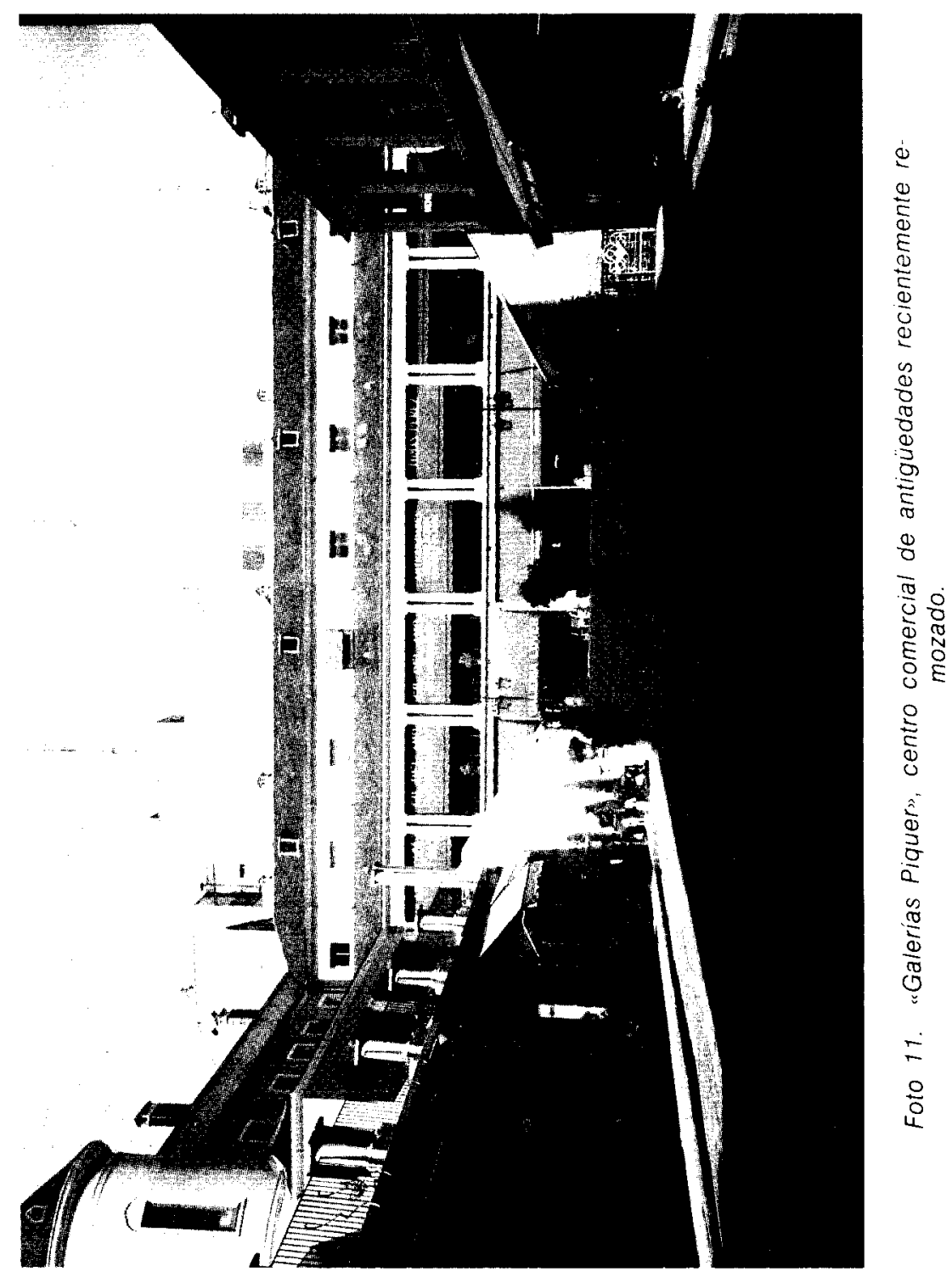




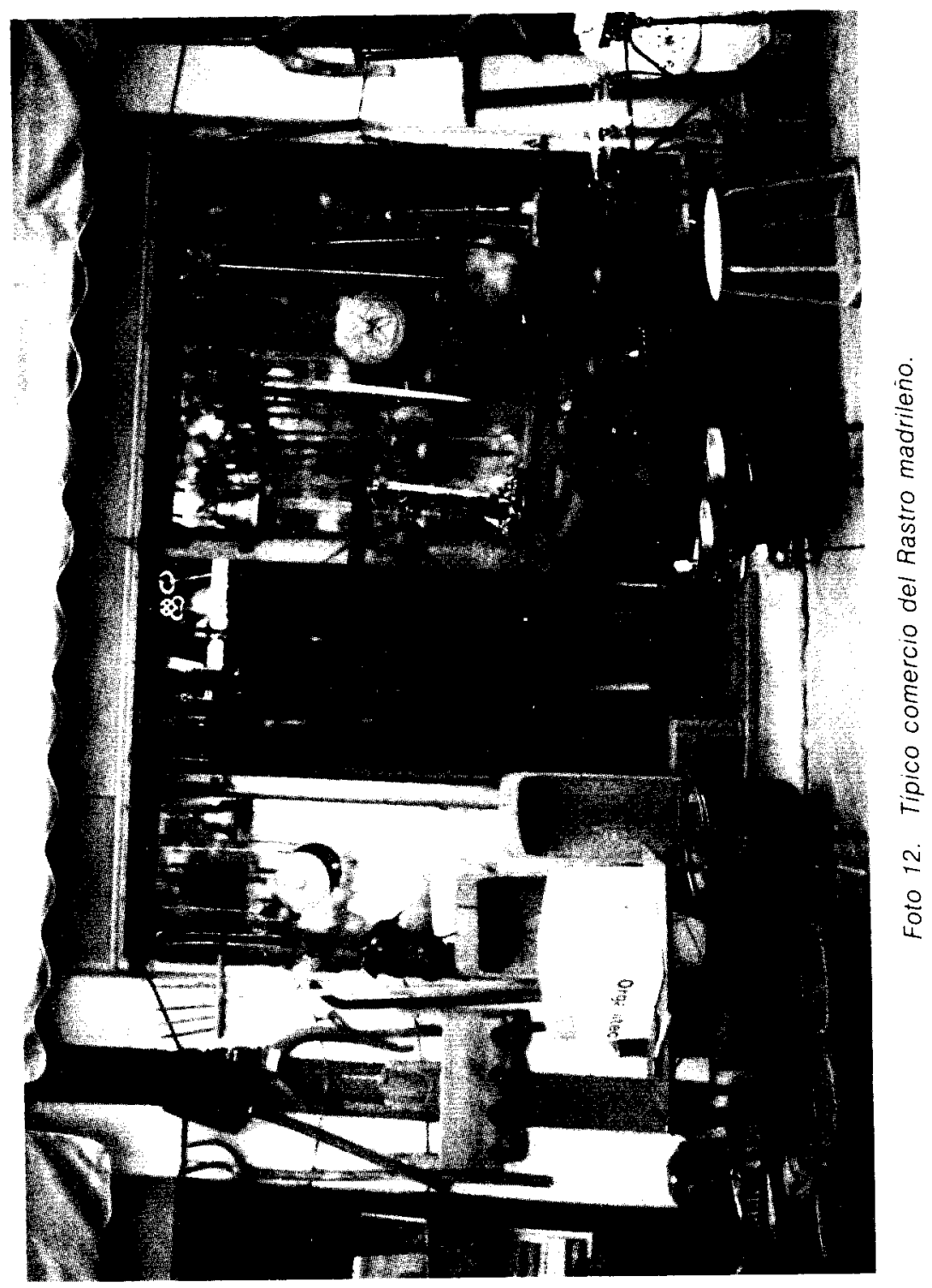


ANEXO. CÓDIGOS DE ACTIVIDADES DEL COMERCIO MINORISTA

100 PRODUCTOS ALIMENTICIOS, BEBIDAS Y TABACO

110 Frutas, verduras y hortalizas (Todos)

111 Frutas

112 Verduras, hortalizas, legumbres

113 Frutas y verduras congeladas

120 Productos lácteos, huevos, aves, caza, aceites, grasas comestibles (Todos)

121 Leche y productos lacteos (excepto Quesos y helados)

122 Quesos

123 Helados

124 Huevos

125 Aves y caza (no congelados)

126 Aves y caza congelados

127 Aceites y grasas comestibles

130 Carnes, charcuteria, casquería (Todos)

131 Carnes (no congeladas)

132 Charcutería, embutidos, jamonería

133 Casquería

134 Carnes congeladas

140 Pescados y mariscos (Todos)

141 Pescados frescos

142 Mariscos (no congelados)

143 Pescados y mariscos congelados

150 Pan, bollería, pastelería, confitería (Todos)

151 Pan

152 Bolleria, pasteleria, confitería

160 Vinos y bebidas (alcohólicas y no alcohólicas)

170 Tabacos

180 Productos alimenticios, sin predominio (tiendas de ultramarinos, comestibles, etc.)

190 Especialidad en otros productos alimenticios no especificados antes (Tiendas especializadas) (Todos)

191 Encurtidos, frutos secos, aperitivos

192 Herboristería, dietéticos, especias

193 Cafés y sucedáneos

194 Platos preparados, precocinados

195 Otros productos no especificados antes

196 Congelados no especificados antes

\section{TEXTILES, CONFECCIÓN, CALZADOS Y ARTÍCULOS DE CUERO}

210 Tejidos por metros, textiles para el hogar (no vestir) y alfombras (Todos)

211 Tejidos por metros para el hogar, textiles para el hogar (no prendas de vestir)

212 Alfombras, moquetas, esteras

220 Prendas exteriores de vestir para hombres, mujeres y niños (Todos)

221 Prendas exteriores de vestir, para hombres

222 Prendas exteriores de vestir, para señora

223 Prendas exteriores de vestir, para niños 
224 Confecciones de lana y punto

225 Otras prendas

230 Camiseria, lenceria, accesorios del vestido, prendas interiores (Todos)

231 Camisería y ropa interior de caballero

232 Lenceria, ropa interior de señora

233 Complementos

234 Otros no especificados antes

240 Mercería, lanas (Todos)

241 Mercería

242 Lanas

250 Calzado, marroquineria, artículos de viaje, peletería (Todos)

251 Calzado

252 Artículos de viaje y bolsos

253 Confecciones de ante, napa y peletería

254 Marroquinería y otros artículos de piel

280 Productos textiles y de cuero (sin predominio)

300 PRODUCTOS FARMACÉUTICOS, PERFUMERIA Y DROGUERIÁA

310 Productos farmacéuticos, (fármacos), Farmacias

320 Drogueria, perfumeria, higiene y belleza (Todos)

321 Droguería

322 Perfumeria, higiene y belleza

400 ARTICULOS PARA EL EQUIPAMIENTO DEL HOGAR

410 Mobiliario (excepto de oficina) (Todos)

411 Muebles cocina y baño

412 Muebles de terraza y jardín

413 Camas, somieres, cunas

414 Otros muebles del hogar (interiores, etc.)

415 Lámparas, iluminación, apliques

416 Otros (cuadros, bellas artes, etc.)

420 Material y aparatos eléctricos, radioeléctricos, electrónicos y electrodomésticos (Todos)

421 Electrodomésticos (excepto TV y video)

422 TV, Video, alta fidelidad (Hi-Fi)

423 Discos, cintas de audio y de video

424 Material eléctrico y electrónico

425 Ordenadores personales

430 Menaje, ferreteria, cerámica y vidrio (Todos)

431 Menaje, ferreteria

432 Cerámica, vidrio, objetos artísticos y de regalo

433 Otros (Chimeneas, piscina, riego, cajas fuertes)

490 Otros artículos para el equipamiento del hogar no especificados antes (Todos)

491 Saneamientos y grifería

492 Material de construcción

493 Revestimientos no-cerámicos

494 Otros especializados 
500 VEHÍCULOS AUTOMÓVILES, MOTOCICLETAS, BICICLETAS Y SUS ACCESORIOS

510 Vehículos y accesorios (Todos)

511 Automóviles (nuevos)

512 Motocicletas (nuevas)

513 Bicicletas (nuevas)

514 Otros vehículos nuevos (embarcaciones, tractores, etc.)

515 Vehículos usados, de ocasión (cualquiera)

516 Accesorios para todos

600 CARBURANTES Y LUBRICANTES

601 Gasolineras con venta de otros productos

602 Gasolineras sin venta de otros productos

\section{OTRO COMERCIO AL POR MENOR}

710 Combustibles: carbones, bombonas de gas, astillas, etc.

720 Muebles de oficina, máquinas y equipos de oficina

730 Aparatos e instrumentos médicos, ortopédicos, ópticos y fotográficos (Todos)

731 Aparatos e instrumentos médico y ortopédicos

732 Aparatos e instrumentos ópticos (Ópticas)

733 Aparatos e instrumentos fotográficos

740 Libreria, papelería, objetos de escritorio, prensa y revistas (Todos)

741 Librería (Libros)

742 Papelería, objetos de escritorio

743 Prensa y revistas

750 Joyeria, relojería, platería, bisutería

760 Juguetes y artículos de deporte y caza (Todos)

761 Juguetes

762 Artículos de deporte y de caza

770 Semillas, abonos, flores, plantas, pequeños animales (Todos)

771 Flores, plantas

772 Semillas, abonos, pequeños animales

780 Productos diversos (sin predominio): Bazar y otros

790 Especialidad en otros productos no especificados antes

800 COMERCIO MIXTO AL POR MENOR, POR SECCIONES

810 Autoservicio (40 a $120 \mathrm{~m}^{2}$ superficie de venta)

820 Superservicios (121 a $400 \mathrm{~m}^{2}$ superficie de venta)

830 Supermercados (más de $400 \mathrm{~m}^{2}$ superficie de venta)

840 Hipermercados

850 Grandes Almacenes (El Corte Inglés, Galerías Preciados, etc.)

860 Almacenes populares (organizados en secciones, pero más pequeños que los Grandes Almacenes). (Más de $500 \mathrm{~m}^{2}$ de superficie de venta)

870 Otros almacenes (Discount y otros)

880 Comercio mixto al por menor en tienda tradicional (en pequeños pueblos)

890 Abierto 24 horas 